\title{
The San Andreas Fault Paleoseismic Record at Elizabeth Lake: Why are There Fewer Surface- Rupturing Earthquakes on the Mojave Section?
}

\author{
Sean P. Bemis ${ }^{* 1}$, Kate Scharer ${ }^{2}$, and James F. Dolan ${ }^{3}$
}

\begin{abstract}
The structural complexity of active faults and the stress release history along the fault system may exert control on the locus and extent of individual earthquake ruptures. Fault bends, in particular, are often invoked as a possible mechanism for terminating earthquake ruptures. However, there are few records available to examine how these factors may influence the along-fault recurrence of earthquakes. We present a new paleoearthquake chronology for the southern San Andreas fault at Elizabeth Lake and integrate this record with existing paleoearthquake records to examine how the timing and frequency of earthquakes vary through a major restraining bend. This restraining bend features a mature, throughgoing right-lateral strike-slip fault, two major fault intersections, proposed subsurface fault dip changes, and a $>200 \mathrm{~km}$ long section of fault misaligned with the regional plate motion. The Frazier Mountain, Elizabeth Lake, Pallett Creek, Wrightwood, and Pitman Canyon paleoseismic sites are located on this relatively linear surface trace of the San Andreas fault between fault bends. Our paleoseismic investigations at Elizabeth Lake document 4-5 earthquakes, since 1100 C.E., similar to the number of earthquakes recorded at Pallett Creek. In contrast, the Frazier Mountain and Wrightwood sites each record 8-9 earthquakes during this same time period. Differences in earthquake frequency demonstrate that fewer earthquakes rupture the central portion of the restraining bend than occur near the fault bends and intersections. Furthermore, the similarity of earthquake records from the Bidart Fan paleoseismic site northwest of the restraining bend and the Frazier Mountain paleoseismic site suggests that the broad, $30^{\circ}$ curve of the Big Bend section of the San Andreas fault exerts less influence on fault rupture behavior than the 3D geometry of the Mojave sections of the fault.
\end{abstract}

\section{KEY POINTS}

- We examine the timing of ground-rupturing earthquakes on a straight section of the southern San Andreas fault.

- The Elizabeth Lake site shows 4-5 paleoearthquakes in 900 yr, versus about 8 on adjacent fault sections.

- Along-fault differences in earthquake frequency appear to correspond with major structural complexities.

Supplemental Material

\section{INTRODUCTION}

What permits seismic rupture to traverse barriers? Empirical and numerical modeling studies of earthquake rupture propagation examine the parameters that allow an earthquake rupture to propagate through a barrier (e.g., Barka and Kadinsky-Cade, 1988; Acharya, 1997; Harris, 1998; Duan and Oglesby, 2005; Wesnousky, 2008; Elliott et al., 2009, 2015;
Lozos et al., 2011; Biasi and Wesnousky, 2017; Douilly et al., 2020). These barriers are typically structural complexities, such as stepovers and bends, in the trace or plane of the fault. Dynamic rupture models of earthquake propagation through bends in strike-slip faults show a common association between bends and rupture termination/initiation (Douilly et al., 2020) and the critical role of inherited stress state from prior earthquakes for the propagation of ruptures through structural complexities (Duan and Oglesby, 2005). Empirical studies (e.g., Biasi and Wesnousky, 2016, 2017) examine surface rupture

1. Department of Geosciences, Virginia Polytechnic Institute and State University, Blacksburg, Virginia, U.S.A., (D) https://orcid.org/0000-0001-7854-6394 (SPB); 2. U.S Geological Survey, Pasadena, California, U.S.A.; 3. Department of Earth Sciences,

University of Southern California, Los Angeles, California, U.S.A.

*Corresponding author: sbemis@vt.edu

Cite this article as Bemis, S. P., K. Scharer, and J. F. Dolan (2021). The San Andreas Fault Paleoseismic Record at Elizabeth Lake: Why are There Fewer Surface-Rupturing Earthquakes on the Mojave Section? Bull. Seismol. Soc. Am. 111, 1590-1613, doi: $10.1785 / 0120200218$

(c) Seismological Society of America

www.bssaonline.org Volume 111 Number 3 June 2021 


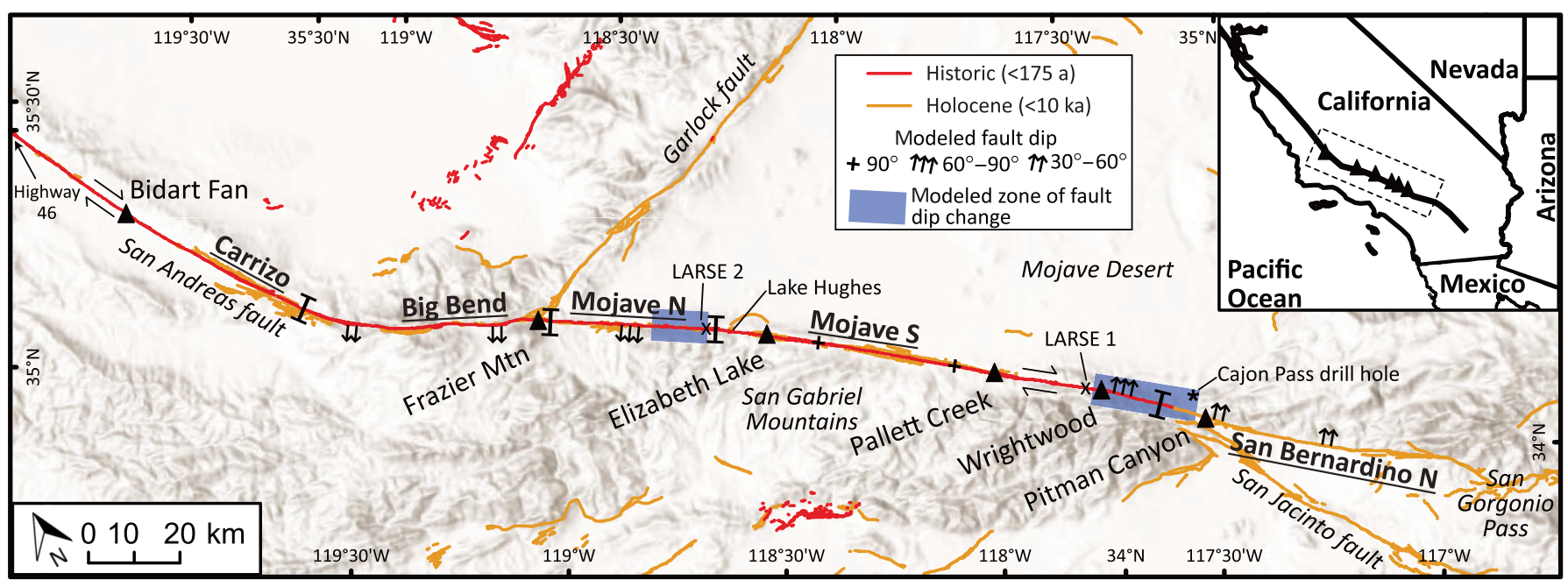

maps of historical earthquakes to characterize the size and geometry of structural complexities associated with the ruptures. From these data, the frequency with which past ruptures propagated through or terminated at bends, gaps, and stepovers can be used to calculate probabilities that, in turn, can be used to constrain potential fault parameters that control rupture propagation or termination. Although, these efforts offer a synoptic view of rupture characteristics and propagation behavior, structural complexity is typically limited to the surface trace of the rupture, rather than the geometry of the fault at seismogenic depths.

The southern San Andreas fault (SSAF) is a long-lived, rightlateral strike-slip fault that accommodates $50 \%-70 \%$ of the total relative motion between the Pacific and North American plates. Among the most prominent, first-order structural features of this fault system are the two major restraining bends that form a $\sim 250 \mathrm{~km}$ long left step in the SSAF fault surface trace. The northern end of this left step-the Big Bend section of the San Andreas fault (SAF; Fig. 1) - exhibits a broadly curved surface trace with $\sim 30^{\circ}$ of total curvature. The southern end of the restraining bend displays more surface trace complexity where the fault exhibits oblique slip for $\sim 40 \mathrm{~km}$ in the San Gorgonio Pass area. Between these fault bends, the SSAF is rotated $\sim 25^{\circ}$ to the motion of the Pacific plate, which contributes to greater compressional stress in the region around the fault (e.g., Yang and Hauksson, 2013). The third Uniform California Earthquake Rupture Forecast (UCERF3; Field et al., 2017) divides the SAF in the restraining bend into four sections: The Big Bend, Mojave north, Mojave south, and San Bernardino north (Fig. 1). Two models for the subsurface geometry of the SAF through the restraining bend differ primarily in the dip of the fault plane through the Big Bend and San Bernardino north sections. The current version of the Southern California Earthquake Center's Community Fault Model (CFM 5.2; Plesch et al., 2007; Nicholson et al., 2017) implements a near-vertical fault plane through the restraining bend. An alternative model, presented by Fuis et al. (2012) and based largely on potential field modeling, depicts a moderately south-dipping
Figure 1. The southern San Andreas fault (SSAF) system and the location of the Elizabeth Lake paleoseismic site. Inset map illustrates the position and orientation of the main figure within southern California. This section of the fault is relatively straight between major restraining bends of the San Andreas fault (SAF). Underlined labels provide the fault section names as defined in the third Uniform California Earthquake Rupture Forecast (UCERF3) (Field et al., 2017), with section boundaries shown by "I" across the fault trace. The Mojave north (N) and south (S) sections are distinguished by a boundary corresponding to $\mathrm{a} \sim 4^{\circ}$ bend in the surface trace of the fault near Lake Hughes. Triangles show the location of well-established paleoseismic sites. " $x$ " shows locations where the Los Angeles region seismic experiment (LARSE) 1 and 2 transects cross the SAF. Fuis et al. (2012) present geophysical models constraining the subsurface geometry of this portion of the SAF, with the shaded boxes depicting where they identify changes in fault dip, from vertical to southwest-dipping on the Mojave north section and vertical to northeast-dipping on the Mojave south section. Quaternary fault traces derived from the 2010 Fault Activity Map of California produced by the California Geological Survey (Jennings and Bryant, 2010). The color version of this figure is available only in the electronic edition.

SAF fault plane for the Big Bend and Mojave north sections, and a moderately north-dipping fault plane for the southeastern Mojave south section and San Bernardino north section. This model requires relatively short along-strike zones for the fault dip to change, with the south-dipping to vertical transition occurring over $\sim 15 \mathrm{~km}$ at the Mojave north-Mojave south section boundary, and the vertical to north-dipping transition occurring over 20-25 km across the Mojave south-San Bernardino north section boundary (Fig. 1). The CFM 5.2 and the Fuis et al. (2012) models agree on a vertical dip for the Mojave south section between the two Los Angeles Region Seismic Experiment (LARSE) transects (Fig. 1). Although several recent studies provide interpretations of fault dip that are consistent with the Fuis et al. (2012) model (Barak et al., 2015; Lee and Chen, 2017; Forand et al., 2018), ambiguity as to whether the modeled fault represents the active fault plane remains. If the interpretations of dipping sections of the SAF 
(a)

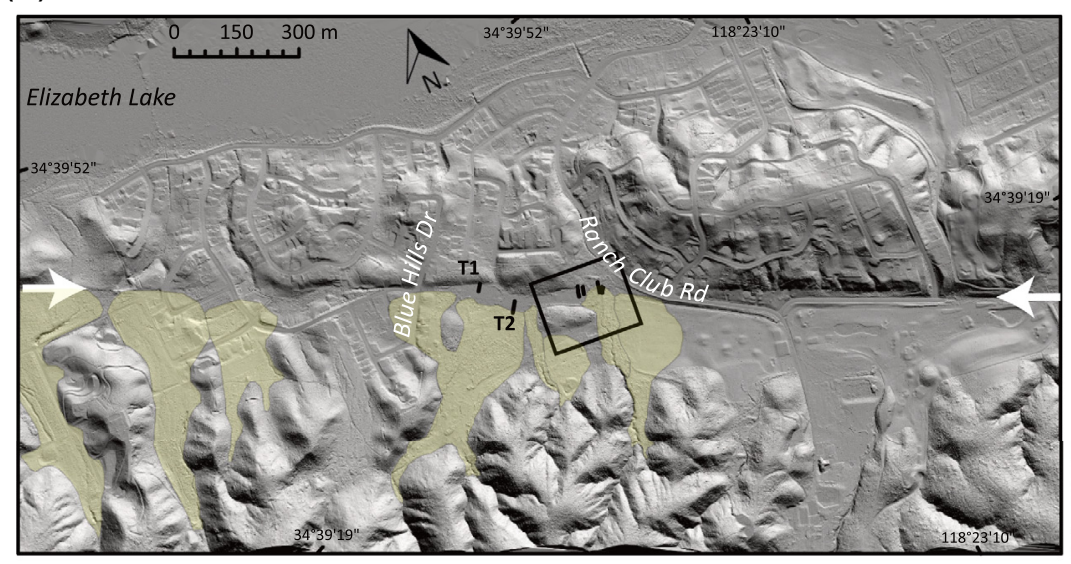

(b)

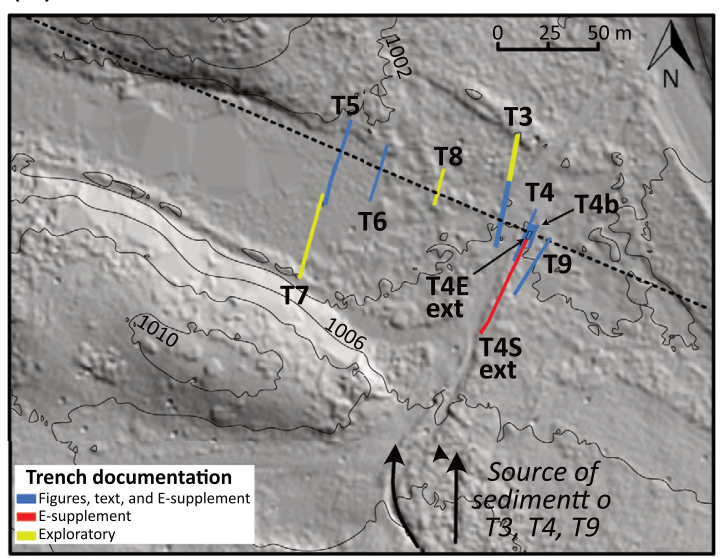

correspond with the active fault plane, these constraints suggest there are significant changes in the fault geometry at depth that are not illuminated by the surface trace (Fig. 1).

The SSAF has generated two known historic surface-rupturing earthquakes, the $1812 \sim M_{\mathrm{w}} 7$ Wrightwood earthquake and the $1857 \sim M_{\mathrm{w}} 7.9$ Fort Tejon earthquake (Sieh, 1978; Jacoby et al., 1988). Paleoseismic and dendrochronologic data show the 1812 Wrightwood earthquake ruptured through the Pallett Creek, Wrightwood, and Pitman Canyon sites (Jacoby et al., 1988; Seitz et al., 1997; Fumal et al., 2002), with the northern rupture extent uncertain over the $100 \mathrm{~km}$ gap between the Pallett Creek and Frazier Mountain paleoseismic sites (Toppozada et al., 2002; Scharer et al., 2017). The rupture extent of the subsequent Fort Tejon earthquake overlapped much of the Wrightwood earthquake and extended an additional $200 \mathrm{~km}$ northwest to Parkfield, California (Sieh, 1978; Scharer et al., 2017). The paleoearthquake record preceding these historic events is well constrained at several widely spaced sites, including the Frazier Mountain paleoearthquake chronology (Scharer et al., 2014, 2017) established at the southernmost end of the Big Bend section, and the Pallett Creek and Wrightwood paleoseismic sites on the Mojave south section (Sieh, 1978; Fumal et al., 2002; Weldon et al., 2002; Scharer et al., 2011) (Fig. 1). The $100 \mathrm{~km}$ gap between these sites is long enough to produce earthquakes as large as $M_{\mathrm{w}} 7.3$, based on magnitude-scaling relationships (e.g., Hanks and Bakun, 2008). Models of paleoruptures that have assumed that earthquakes traverse this gap (Scharer et al., 2017; Scharer and Yule, 2020) could overestimate magnitude of paleoearthquakes due to potential miscorrelation of events between sites. Given its position, filling this gap allows us to use the along-fault paleoearthquake records to test ideas of earthquake behavior relative to fault geometry and prior earthquake history.

Major fault geometric features such as bends in the fault trace, changes in the amount and direction of fault dip, and overall obliquity of the SSAF in the restraining bend, influence how the regional stress field is resolved onto the fault plane. This static state of stress on the fault plane can then interact
Figure 2. The Elizabeth Lake paleoseismic site. (a) The uphill-facing SAF scarp occurring upslope from Elizabeth Lake. Semitransparent polygons depict alluvial fan deposits from the north-flowing drainages dammed by the fault scarp. The black rectangle shows the extent of (b). White arrows highlight the trace of the SAF. (b) Detailed map of the southwestern portion of the Elizabeth Lake trench site, with each trench colored according to the level of documentation (a 1998 exploratory trench, not shown for clarity, was approximately coincident with the shallow portions of T4). Exploratory trenches were primarily used to test for faulting beyond the primary fault zone and are not detailed further here. Our excavations span the entire width of the prospective fault zone in multiple locations, ultimately limiting the fault zone to within $\sim 10 \mathrm{~m}$ of the fault trace shown (black dotted line). Contour interval $=2 \mathrm{~m}$. Topographic data derived from the B4 light detection and ranging (lidar) dataset (Bevis and Hudnut, 2005). The color version of this figure is available only in the electronic edition.

with the dynamic behavior of earthquake ruptures to impede or promote rupture propagation (e.g., Douilly et al., 2020). To examine how these geometric changes might influence earthquake ruptures through this restraining bend, we established the new Elizabeth Lake paleoseismic site on the Mojave south section of the SAF (Fig. 1). This site is located about halfway between the Frazier Mountain and Pallett Creek paleoseismic sites (Fig. 1). We describe the evidence for up to five SAF ground-rupturing earthquakes during the past $\sim 900 \mathrm{yr}$ at the Elizabeth Lake site, based on observations from six trenches excavated across the fault. When compared with the paleoseismic record at neighboring sites, the new chronology of paleoearthquake ruptures at Elizabeth Lake demonstrates that the Mojave south section of the SSAF ruptures less frequently than adjacent fault sections. The along-fault changes in earthquake frequency appear to correspond with large-scale geometry changes of the SAF, and these geometry changes are likely acting to limit the propagation of some earthquake ruptures.

\section{THE ELIZABETH LAKE PALEOSEISMIC SITE}

Along the northern end of the Mojave south section, the active trace of the SAF occupies the southwestern margin of a long axial valley that traps sediment shed northeastward from the San

www.bssaonline.org Volume $111 \quad$ Number 3 June 2021 
(a)

(b)

T5

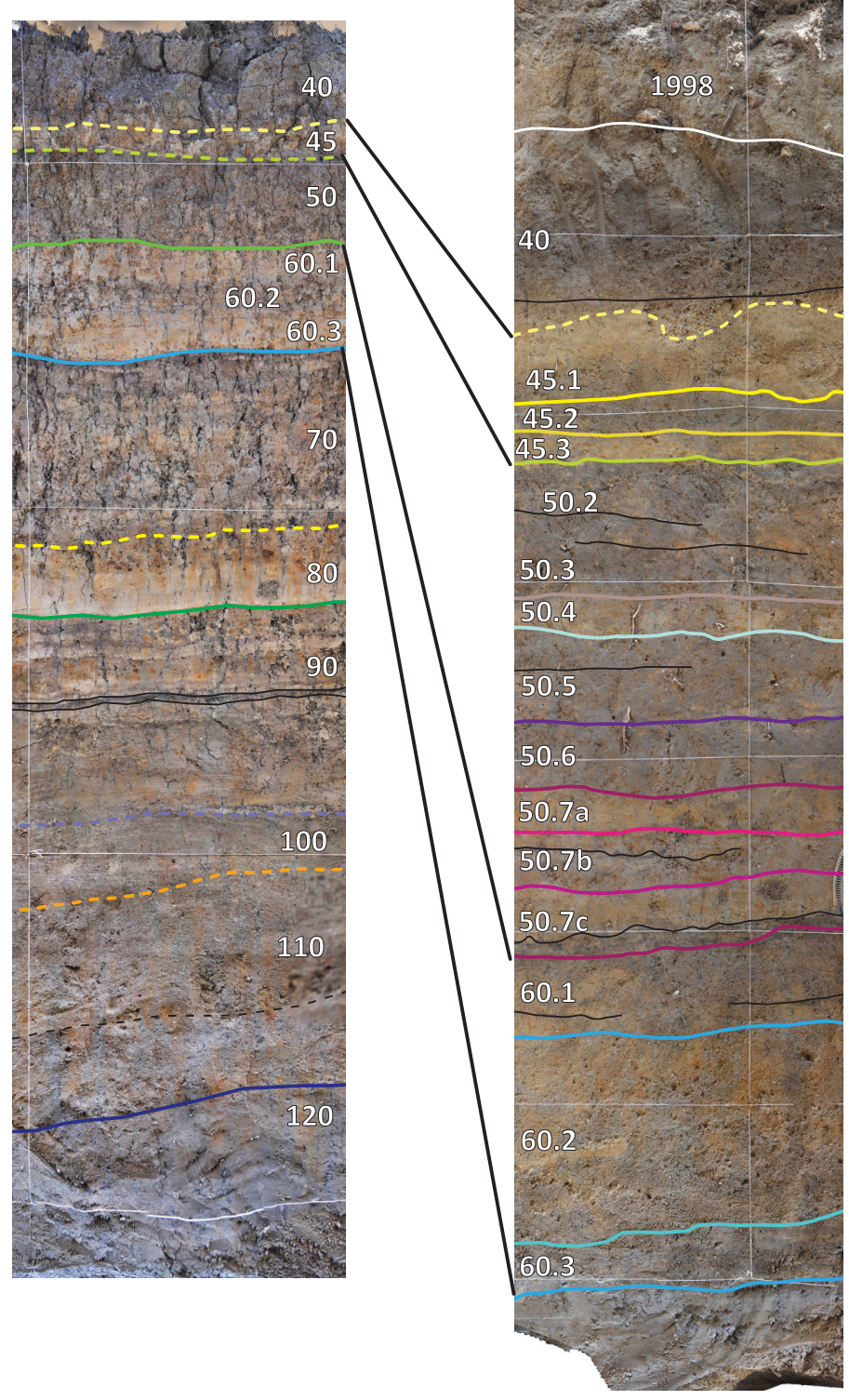

(c)

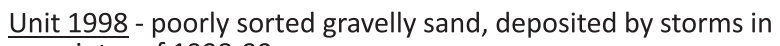
winter of 1998-99

$\underline{\text { Unit } 40}$ - gravelly sand, sand, sandy silt

Unit 45.1 - bioturbated, moderately-sorted fine sand

Unit 45.2 - sand and organic-rich silt

Unit 45.3 - fining-upward, well-sorted sand

Units 50.1, 50.2, 50.3 - bioturbated clayey silt and sand with weakly-defined bedding

Unit 50.4 - fine sand, krotovina common

Unit 50.5 - organic-rich clayey silt with blobs of orange-tan fine sand

Unit 50.6 - organic-rich clayey silt

Unit 50.7a - silty fine sand with local bioturba囚on

Unit 50.7b - clayey silt and fine sand, thin charcoal-rich horizon

Unit 50.7c - silty fine sand, krotovina, thin charcoal-rich horizon at base

Unit 60.1 - moderately sorted fine to medium sand

Unit 60.2 - moderately sorted coarse sand

$\underline{\text { Unit } 60.3}$ - moderately sorted fine-medium sand

$\underline{\text { Unit } 70}$ - well-bedded clayey silt and sandy silt

Unit 80 - well-sorted fine-medium sand

Unit 90 - well-bedded clayey silt and sandy silt

Unit 100 - massive very fine to medium-grained sand

$\underline{\text { Unit } 110}$ - well-sorted, massive bedded coarse sand

Unit 120 - massive clay to clayey silt
Figure 3. Elizabeth Lake paleoseismic site stratigraphic section and cross-site unit correlations. Key examples of the lower stratigraphy from (a) T5 and the upper stratigraphy from (b) T9, with lines showing our interpretation of unit correlations between trenches. These correlations between eastern and western trenches are based on textural observations and supported by radiocarbon dating. (c) Basic sedimentologic descriptions for each unit include the most common characteristics of each unit, although, there are minor grain-size variations across the site and a general increase in grain size upslope (southward) from the fault. (d) Fault-parallel unit correlations. Unit contacts and thicknesses are representative values measured between 1 and $3 \mathrm{~m}$ south from the main fault zone. White rectangles with enclosed numbers show the stratigraphic location of evidence for earthquakes EL1-4. The persistent trend of northwest-dipping units records the alluvial character and typical source of these deposits. The color version of this figure is available only in the electronic edition.
(Continued)
Gabriel Mountains (Figs. 1 and 2). Along this reach, the fault zone forms an uphill-facing scarp that dams and offsets northflowing drainages emanating from the adjacent mountains. Geomorphic and vegetation patterns indicate that shallow groundwater is present along much of the valley. We targeted a large fault-parallel depression that is situated in an undeveloped zone between Blue Hills Drive and Ranch Club Road
(Fig. 2). Satellite imagery since 1994 shows fluctuations in the amount of surface water in this depression, with a drying trend between 2008 and 2012 prior to beginning our work at the site. Alluvial fans and channels show that most sediment at the site is derived from three small catchments $\left(<0.3 \mathrm{~km}^{2}\right.$ each). Given the topography, the site may also episodically receive sediment from a larger catchment $\left(2.2 \mathrm{~km}^{2}\right)$ to the southeast (Fig. 2a). The 


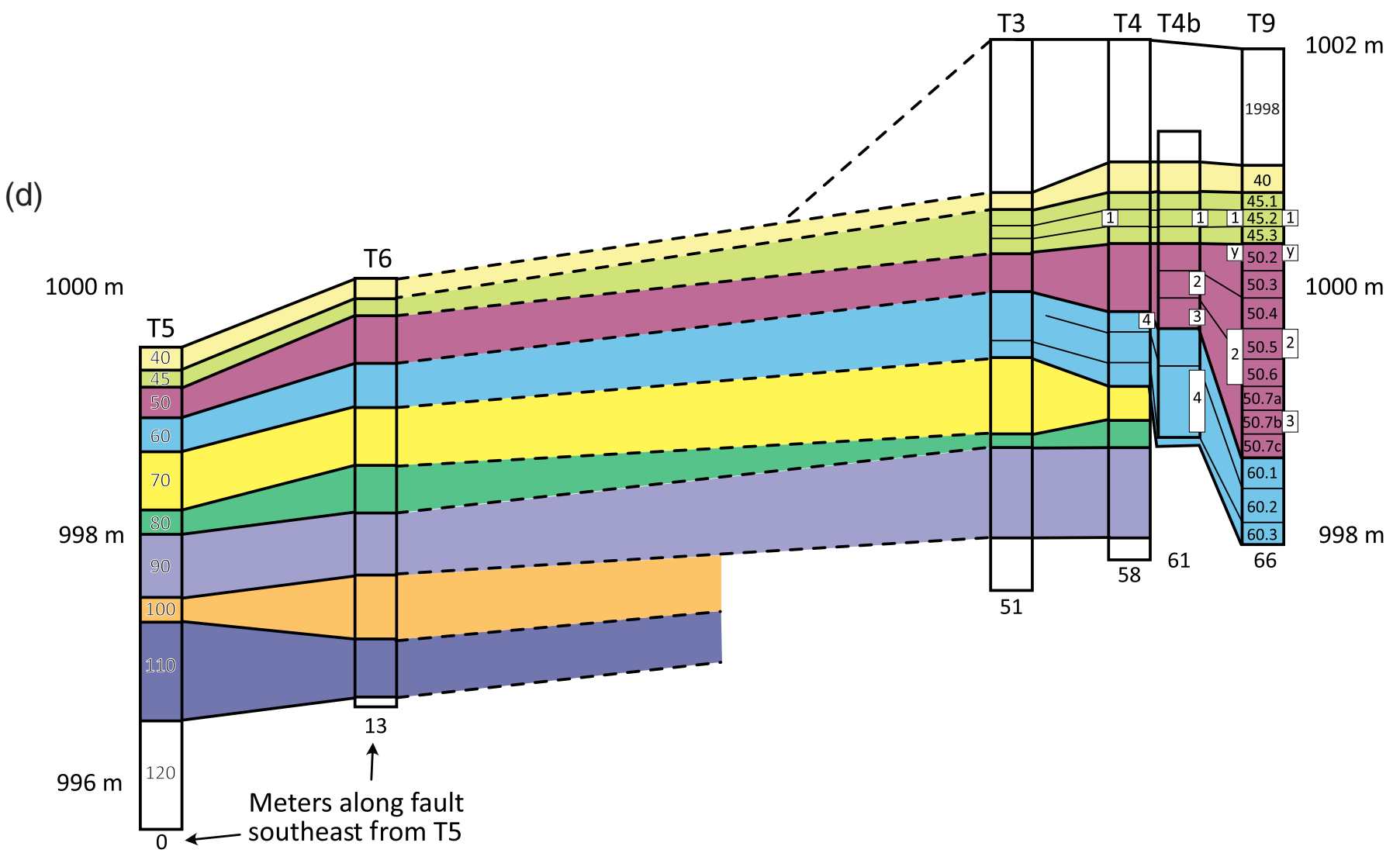

Figure 3. Continued

southeastern portion of the site was covered in $\sim 1 \mathrm{~m}$ of sediment during the $1998 \mathrm{El} \mathrm{Nino} \mathrm{event} \mathrm{(Figs.} 3$ and 4), and a $10 \mathrm{~cm}$ thick deposit of sand and gravel in storms following the 2013 Powerhouse fire, which burned the hills above the site.

In total, our paleoseismic investigations consist of 10 faultperpendicular trenches that cross the depression (Fig. 2) and expose a $>2000 \mathrm{yr}$ long depositional record. These trenches reveal that the thickest section of young stratigraphy is preserved at the southeastern end of the site where the fault zone crosses through a northeast-flowing ephemeral drainage. Correspondingly, this southeastern end of the depression best preserves the stratigraphic record associated with recent earthquakes and is the primary focus of this article.

Of the 10 trenches at the Elizabeth Lake paleoseismic site, seven provided well-defined stratigraphy that could be readily correlated to nearby trenches. The westernmost of these trenches (T5, T6, and T7) were excavated through the deepest portion of the modern fault-parallel depression, extending northward from the geomorphic fault scarp across the middle of the depression (Fig. 2). The other four trenches (T3, T4, T4b, and T9) and associated extensions (T4E ext, T4S ext) were excavated into an alluvial fan that extends across the fault trace at the southeastern end of the fault-parallel depression. These southeastern trenches reveal transpressional and transtensional structures within the fault zone, providing juxtaposition of stratigraphic units and soils.

\section{TRENCH STRATIGRAPHY}

The stratigraphy of trenches $\mathrm{T} 3-\mathrm{T} 9$ is characterized primarily by fine-grained, organic-rich deposits with intermittent coarsergrained alluvial deposits (Fig. 3; Table 1). The alluvial input varies across the site, with T5-T7 containing generally finer-grained deposits due to a small hill blocking direct sediment input from the north-flowing drainages (Fig. 2). An ephemeral drainage that passes immediately southeast of this small hill is the source of the greater alluvial input to the T3, T4, T4b, and T9 area. The uppermost unit in these trenches was deposited following heavy precipitation associated with the $1998 \mathrm{El}$ Nino climatic event. The basal contact of the 1998 deposits is locally defined by an asphalt road surface (partially exposed in T4 ext) or a thin layer of bentonite (in the east wall of T4 and T4b). The 1998 deposits do not appear in T5-T7. Below the 1998 deposits in the closely spaced $\mathrm{T} 3, \mathrm{~T} 4, \mathrm{~T} 4 \mathrm{~b}$, and T9 trenches, the upper stratigraphic section (units 40-60.3) increases in thickness from 2 to $3 \mathrm{~m}$ toward the southeast (Fig. 3). In T3 and T4, unit 50 varies in thickness from $\sim 30$ to $70 \mathrm{~cm}$ and typically thins across structural highs 


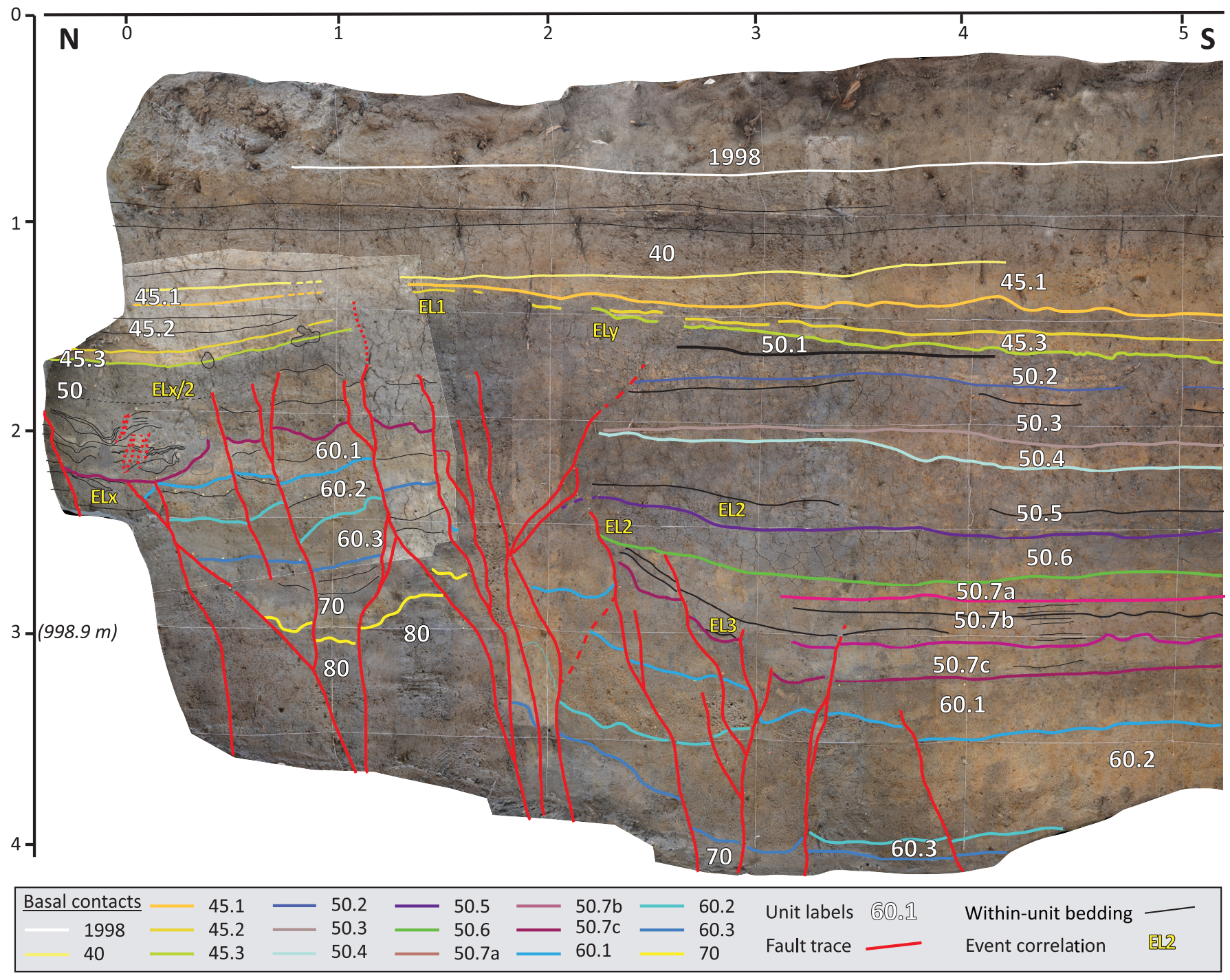

(Figs. S4-S8, available in the supplemental material to this article). Southeastward from T4, unit 50 thickens across T4b and T9, expanding to $1.5 \mathrm{~m}$ thick with nine well-defined subunits (Figs. 3 and 4, Figs. S1 and S9). Cross-trench elevation differences of subunits within unit 50 indicate a gentle dip to the southeast from T4 to T9; this dip decreases upsection such that the basal contact of 45.3 is close to horizontal from T3 to T9 (Fig. 3). Unit 50 thins from $\sim 0.5$ to $<0.2 \mathrm{~m}$ over $3-4 \mathrm{~m}$ north of the fault zone (Figs. 4 and 5), and farther north becomes indistinguishable from the adjacent units. The thickness and relative grain sizes of unit 60 vary between trenches, but the sequence of a coarser-grained layer between two finer-grained layers is persistent. The basal contact of unit 60 occurs as a consistently sharp boundary between sandy sediments above and clayey silt below within the fault zone, and extends $>10 \mathrm{~m}$ to the north (e.g., T3). This stratigraphic contact becomes less distinct $\sim 7 \mathrm{~m}$ south of the fault zone, as the entire stratigraphic sequence becomes generally coarser-grained in the upslope direction. Units below 60.3 are not as stratigraphically distinct and consequently exhibit unclear correlations across fault zones and between trenches. The relationships between units 70 ,
Figure 4. Portion of the east wall of T9 showing key faulting and stratigraphic relationships. The stratigraphic thickness of unit 50 increases markedly to the south across the main fault zone between 1 and $2 \mathrm{~m}$. Horizontal distances on the trench logs are measured relative to a line fit through the location of ELx evidence in each trench, with positive distance values to the south and negative distance values to the north. The ELx/2 label corresponds with the location of earthquake evidence described in Table 3 and is used to indicate that this evidence is correlated with either ELX and/or EL2. The color version of this figure is available only in the electronic edition.

80 , and 90 are the best preserved within downdropped portions of the fault zone, whereas, where these units occur structurally higher, the contacts and sedimentological characteristics are overprinted by soil-forming processes.

The upper stratigraphic section in trenches $\mathrm{T} 5$ and $\mathrm{T} 6$ exhibits a sequence of units that is correlative with T3, T4, and T9; however, the deposits in T5 and T6 are generally finer-grained and exhibit an overall fining-upward sequence (Figs. 3 and 6; Figs. S10-S13). The sediments are separated from sheared bedrock across two subvertical fault zones and 
TABLE 1

Descriptions of Stratigraphic Units at the Elizabeth Lake Paleoseismic Site

\section{Units of T3, T4, T4b, and T9}

Unit Description

1998 50-100 cm thick; poorly sorted gravelly sand; deposited by storms in the winter of 1998-1999

$40 \quad 10-50 \mathrm{~cm}$ thick; discontinuous horizons of gravelly sand, sand, and sandy silt; sediments coarsen with distance south of fault zone (i.e., upslope)

45.1 5-10 cm thick; locally bioturbated, moderately sorted, fine-grained sand; sharp basal contact

45.2 $\sim 0 \mathrm{~cm}$ thick across structural highs, up to $30 \mathrm{~cm}$ thick in depressions; sandand organic-rich silt near-fault zone, coarser grained $>5 \mathrm{~m}$ south of fault zone

$45.3 \quad 5-10 \mathrm{~cm}$ thick; well-sorted, fining upward sand; sharp basal contact

50.1 Bioturbated clayey silt; diffuse basal contact

50.2 Strongly bioturbated, fine-grained sand; mottled tan-orange

50.3 Bioturbated clayey silt

$50.4 \quad 5-15 \mathrm{~cm}$ thick fine-grained sand; numerous krotovina (filled animal burrows)

$50.5 \quad 15-40 \mathrm{~cm}$ thick; massive organic-rich clayey silt; irregularly shaped lenses of orange-tan fine sand

50.6 15-40 cm thick; massive organic-rich clayey silt

50.7a 5-10 cm thick; silty fine-grained sand; local bioturbation

$50.7 \mathrm{~b} \quad 5-15 \mathrm{~cm}$ thick; clayey silt and fine-grained sand; thin charcoal-rich horizon

50.7c 10-15 cm thick; silty fine-grained sand; krotovina; thin, dark, charcoal-rich horizon at base, with sharp basal contact

60.1 Fine- to medium-grained sand; thickness varies between trenches, locally absent; clear basal contact

$60.2 \quad 20-50 \mathrm{~cm}$ thick; massive, coarse-grained sand

$60.3 \quad 10-30 \mathrm{~cm}$ thick; moderately sorted fine- to medium-grained sand; sharp basal contact

$70 \quad 10-30 \mathrm{~cm}$ thick; clayey silt with local cm-scale sandy silt interbeds

$80 \quad 10-20 \mathrm{~cm}$ thick; well-sorted fine- to medium-grained sand

90 Silty sand to clayey silt with diffuse, decimeter-scale bedding

Silty sand with $5-10 \mathrm{~cm}$ scale internal bedding defined by variations in silt content; sharp basal contact

110 Massive, silty, very coarse-grained sand
Units of T5 and T6

Unit Description

40 Bioturbated, clayey, organic-rich silt topped with a thin O horizon

$45 \sim 10 \mathrm{~cm}$ thick fine-grained sand; extensively bioturbated; subunits indistinguishable; clear basal contact

20-30 cm thick; massive to locally bedded clayey silt and sand; clear basal contact

$60.1 \sim 10 \mathrm{~cm}$ thick; well-sorted, very fine- to fine-grained sand

$60.2 \sim 10 \mathrm{~cm}$ thick; well-sorted, fine- to medium-grained sand

$60.3 \sim 10 \mathrm{~cm}$ thick; well-sorted, very fine- to fine-grained sand; sharp basal contact

$70 \sim 50 \mathrm{~cm}$ thick; well-bedded sequence of clayey silt and sandy silt horizons; internal contacts diffuse, but individual beds continuous

$80 \quad 15-20 \mathrm{~cm}$ thick; well-sorted fine- to medium-grained sand; sharp basal contact; upper portion of unit contains extensive bioturbation and Fe-Mn oxide nodules, lower section unaltered

90 Alternating $2-5 \mathrm{~cm}$ thick beds of clayey silt with sharp contacts in upper portion of unit; lower portion has thicker beds with more diffuse contacts

100 Very fine- to medium-grained sand; no internal bedding

110 Well-sorted coarse-grained sand; increasing silt and clay content near top of unit

120 Massive clay to clayey silt; base of unit not exposed an intervening 2-3 $\mathrm{m}$ wide zone of relatively homogeneous gravelly silt and clay (Fig. 6). The fault zones occur at the base of the $\sim 2 \mathrm{~m}$ tall, 10-12 m wide, gently sloped fault scarp face (Fig. 2). No stratigraphic units cross the fault zone. Bedrock is exposed to the northeast of the fault zones, and exhibits pervasive shears and fractures.

\section{EARTHQUAKE EVIDENCE}

Our investigations exposed the full width of the fault zone in two locations-the directly overlapping trenches T5 and T7 and the T3, T4, and T9 set of trenches (Fig. 2). The long exposure of undeformed bedding in the southern end of T5 and T7 demonstrate that recent deformation is localized within a few meters of the main fault zone in T5. Similarly, stratigraphic offsets associated with the fault zone are captured entirely in T4, with the southern extension of T4 exposing undeformed sediments (Fig. 2, Figs. S2 and S3) south of the fault zone and T3 containing the unfaulted basal contact of unit 60 extending northward from the fault zone (Figs. S4 and S5). The upper stratigraphic section across the fault zone, from unit 60 to 


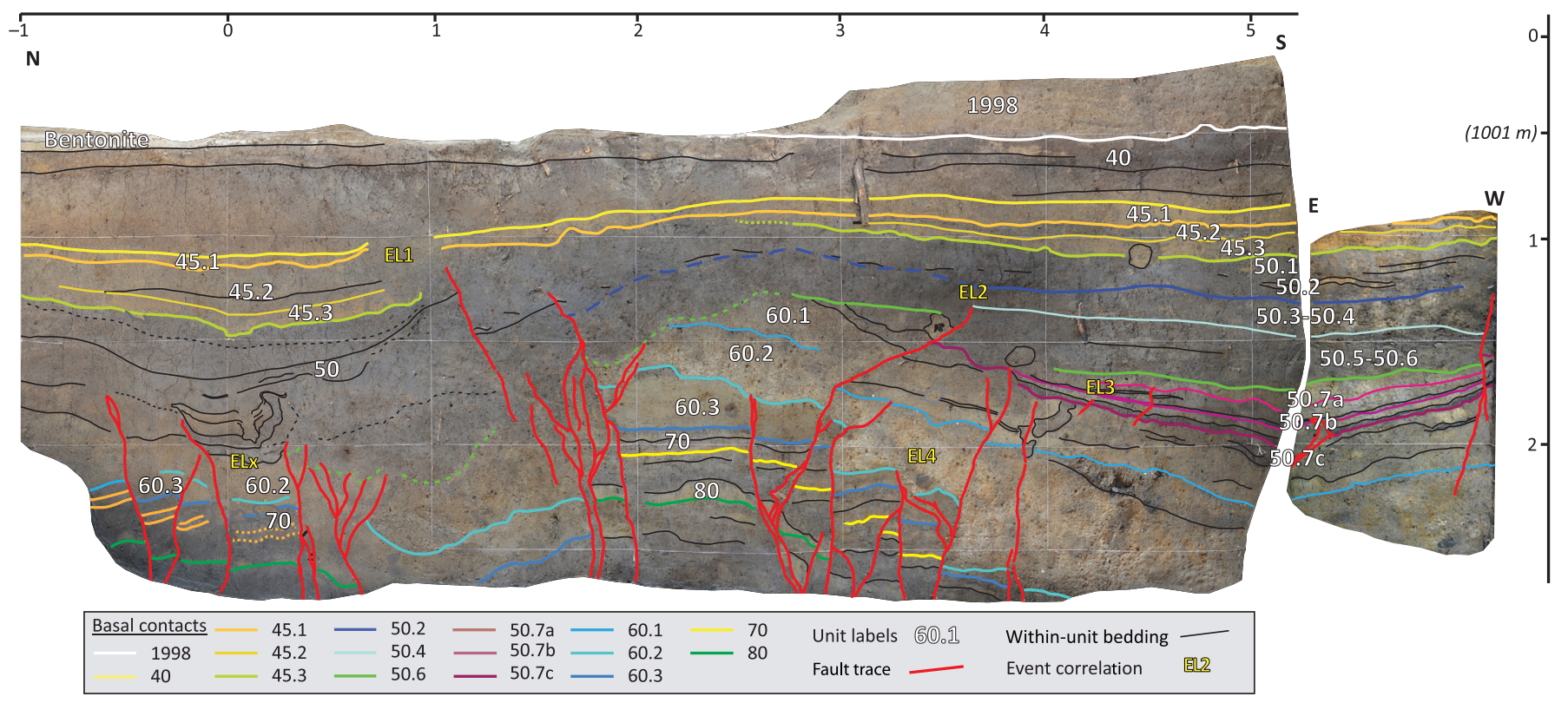

the historical 1998 deposit, is $\sim 3.7 \mathrm{~m}$ thick in T9 and thins northwestward to $\sim 2.3 \mathrm{~m}$ in T4 (Fig. 3). Most of this thickness change occurs within unit 50 , which is a $\sim 0.5 \mathrm{~m}$ thick, massive organic-rich clayey silt in T4 that expands to a $1.4 \mathrm{~m}$ thick succession of interbedded sand and clayey silt in T9. Complete details on locations of event evidence on the individual trench walls are presented in Table 2. Locations of trench wall features mentioned in the text are described by their horizontal position on the trench $\log$ (e.g., meter 8; or between meters 7 and 9).

\section{Event 1-EL1}

The most recent event recorded at Elizabeth Lake (EL1) is defined by a southwest-side-up vertical separation of units 45.3 and younger on faults extending up to within $50 \mathrm{~cm}$ of the 1998 deposit basal contact (Figs. 4 and 5, Figs. S1, S6, S8, and S9). Deformation associated with this earthquake forms a low amplitude ( $\sim 20-30 \mathrm{~cm}$ high) pop-up structure in the southeasternmost trenches (T4b, T9), transitioning to a simple vertical separation to the west at T4. Unit 45.3 exhibits a consistent thickness where present on both sides of the zone of faulting, except where it is truncated by the fault and absent for $\sim 2 \mathrm{~m}$ on the upthrown side of the fault. On the south side of the pop-up, unit 45.3 is gently tilted to the south. Above this, unit 45.2 appears to cross-cut 45.3 , forming a very subtle angular unconformity. However, these contacts are partially overprinted by bioturbation and soil development, making this relationship indistinct. In all exposures, 45.2 is significantly thicker on the north side of the fault zone. Although, the basal contact of unit 45.1 is indistinct across the EL1 fault trace in T9 and T4b, it is clearly unfaulted across the fault zone in T4E ext (meters 0.5 to 1 in Fig. S8).

We interpret EL1 as having occurred during the deposition of unit 45.2 based on: (1) no cross-fault thickness change of 45.3 ,
Figure 5. Photomosaic and log of the T4b east wall. The southern end of the trench wall is shown rotated $90^{\circ}$ into the same perspective as the main wall. North-south and east-west indicate the approximate orientations of the originally perpendicular wall sections. The lower subunits of unit 50 exhibit increasing dip, with depth to the southeast in the trench. The main fault zone bounds a 1-2 m wide pop-up structure. Below unit 45.3, contacts cannot be traced continuously across the pop-up structure, preventing correlation of ELx deformation with the higher-resolution stratigraphy of unit 50 preserved south of the pop-up. The top of the photomosaic is below the ground surface, because the 1998 deposits were disturbed during excavation of prior, adjacent trenches. The color version of this figure is available only in the electronic edition.

despite localized erosion across a structural high; (2) apparent folding of 45.3; (3) thickness change of 45.2 across the fault; (4) apparent stratigraphic onlapping relationships within 45.2; (5) thickness change in 45.1, consistent with accumulation across minor surface relief associated with the fault zone; and (6) lack of faulting across the base of 45.1. The relief produced during the earthquake led to localized erosion at the top of the pop-up, redepositing the sediments of units 45.3 and lower 45.2 in the thickened section of 45.2 on the north side of the fault. The swale on the downthrown side was largely filled prior to the deposition of 45.1 .

The stratigraphically highest evidence for this rupture appears near meters 1 and 2 in T5 (Fig. 6) and meters -1 and 0 in T6 (Figs. S12 and S13), in which the fault zone that separates bedrock from sheared sediments appears to penetrate up into the base of modern soil horizons. In both the trenches, there is a package of coarser-grained sediment (labeled "CW?") immediately south of and downslope from the prospective surface rupture that is consistent with the occurrence of a recent rupture on the geomorphic scarp. Organic-rich sediments overlying the clastic deposit appear to be consistent with unit 40 . 


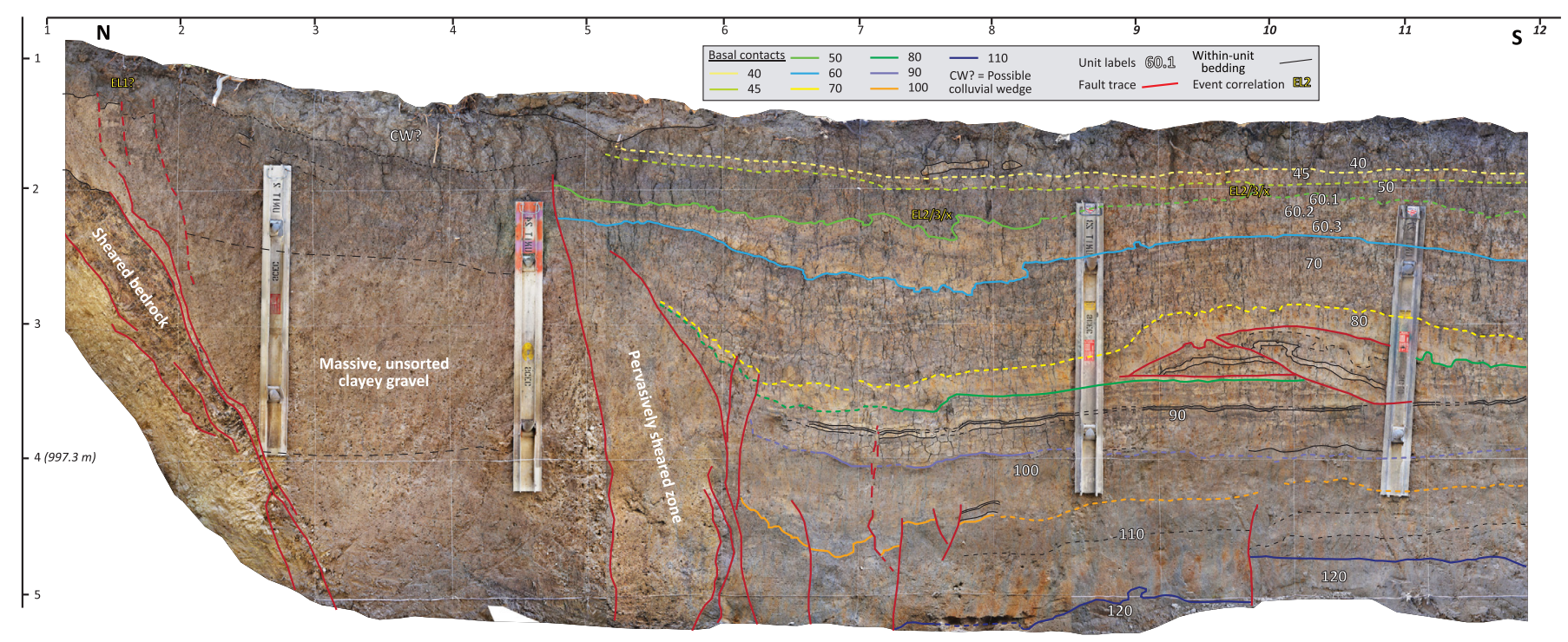

\section{Event 2-EL2}

A prior deformation event occurs in the middle portion of unit 50 , involving units 50.5 and 50.6. In T4b, a single fault strand cuts across unit 50.6 and likely unit 50.5 , and is overlain by unit 50.2 and, possibly, the poorly differentiated section of 50.350.4 (meters 3 to 3.5 in Fig. 5). The upward termination of these faults is obscured by diffuse stratigraphic relationships and a krotovina; however, thickness and textural changes in the units below 50.3 and 50.4 support the observed extent of faulting. Deformation during this same stratigraphic interval in T9 (Fig. 4) is expressed as distributed folding and minor faulting that affects units below 50.4 between meters 2 and 3.5. In T9W (Fig. S1), the stratigraphic section between units 50.4 and 60.1 doubles in thickness across a series of down-to-thesouth faults from meters 2.5 to 3.5. Faults that cut through this thickness change are constrained to have occurred after 50.7 and prior to 50.4. T9E exhibits deformation of this section as broad folding between meters 2 and 3 that affects units 50.5 and below, with the top of 50.4 not folded in the same fashion (Fig. 4). Parallel to the fault, there is about $1 \mathrm{~m}$ of thickening of the middle section of unit 50 ( units 50.5 and 50.6) in the seven meters between T4 and T9. This reflects deposition following a folding event that could have occurred sometime between the top of 50.7 and the base of 50.3 that is consistent with constraints on EL2.

The contrast between the broadly deformed basal contact and the horizontal upper contact of unit 50 in trenches T5 and T6 demonstrates the occurrence of, at least, one earthquake during deposition of this unit. In T5, a well-defined thrust duplex within units 80 and 90 created a $3-4 \mathrm{~m}$ wide fold involving the overlying sediments up to the basal unit 50 (Fig. 6). The basal contact of unit 45 is unaffected by this fold, indicating that it occurred during deposition of unit 50. In T6, two faults between meters 6 and 8 displace a block of unit 60 and clearly do not deform the base of unit 45 . Subvertical faults near meters 4 and 5 in T5 and meters 3 and 4 in T6 all
Figure 6. Portion of the west wall of trench 5 showing the transition from bedrock to ponded sediments across the primary fault zone. The wellbedded stratigraphy to the south is truncated against the massive, pervasively sheared rock and sediment that comprise the $\sim 3 \mathrm{~m}$ wide fault zone. Structural duplexing within units 80 and 90 folded the overlying sediments up to lower unit 50, which is capped by a horizontal unit 45 . Lacking internal stratigraphy in this section, we can only correlate this deformation with one of the earthquakes that occurred during deposition of unit 50-EL2, EL3, or ELx. Additional secondary faults cut the lower stratigraphy, but minor displacements and upward terminations made these unreliable for earthquake evidence. Italicized horizontal grid numbers provide corrected horizontal values from an error in the measured distance between the vertical grid lines as established in the field. The color version of this figure is available only in the electronic edition.

correspond with the truncation of well-bedded stratigraphy, and, on each wall, at least, one of these faults appears to cut the basal contact of unit 50. Unfortunately, poor stratigraphic resolution prevents distinguishing these ruptures from the other events that deform the base of unit 50, allowing these lines of earthquake evidence to also be associated with EL3 or ELx.

\section{Event 3-EL3}

Evidence for EL3 consists of the angular relationship between unit 60 and the overlying subunits $50.7 \mathrm{a}-50.7 \mathrm{c}$ in T4b and T9 (occurring between meters 2.5 and 3.5 in Fig. 4 and meters 4 and 5 in Fig. 5). Best illustrated in T4b, the basal subunit (50.7c) has a steeper dip than the upper subunits, as demonstrated by the decrease in unit 50.7 thickness from meters 5 to 4 and how the basal contact of 50.5-50.6 converges with the basal contact of 50.7c near meter 4 (Fig. 5). From this evidence, we interpret a faulting and folding event that warps units $50.7 \mathrm{c}$ and older, creating accommodation space for $50.7 \mathrm{~b}$ and $50.7 \mathrm{a}$. Despite only two clear exposures of event evidence (T9E and $\mathrm{T} 4 \mathrm{~b}$ ), we interpret the structural-stratigraphic relationships as 


\begin{tabular}{|c|c|c|c|c|c|c|c|c|}
\hline Sample Name & CAMS Lab ID & Trench & Wall & Unit* & Sample Type & ${ }^{14} \mathrm{C}$ age $(\mathrm{yr} \text { B.P. at } 1 \sigma)^{\dagger}$ & $\delta^{13} C^{\ddagger}$ & Trench Log Code \\
\hline EL9E-B5.1 & 169930 & 9 & E & 50.1 & Charcoal & $220 \pm 30$ & -25 & B5 \\
\hline EL9E-B9 & 174953 & 9 & E & $50.4-9$ & Charcoal & $655 \pm 25$ & -26.3 & B9 \\
\hline EL9E-B9A & 174848 & 9 & E & $50.4-9$ & Seed & $425 \pm 25$ & -26.3 & B9 \\
\hline EL9E-B11B1 & 174952 & 9 & $\mathrm{E}$ & $50.6-1$ & Plant remains & $570 \pm 35$ & -25 & B11B \\
\hline EL4.2-M2 & 174955 & $4 b$ & $S$ & $50.5-2$ & Charcoal & $760 \pm 25$ & -26.5 & $\mathrm{M} 2$ \\
\hline EL4.2-M2 & 174852 & $4 b$ & $S$ & $50.5-2$ & Charcoal & $750 \pm 25$ & -26.5 & M2 \\
\hline EL4.2-M3.5 & 169927 & $4 b$ & $S$ & $50.7 c$ & charcoal & $935 \pm 30$ & -25 & M3 \\
\hline EL4.2-M3.8 & 169929 & $4 b$ & $S$ & $50.7 c$ & Charcoal & $865 \pm 30$ & -25 & M3 \\
\hline EL4.2-M3.3 & 169925 & $4 b$ & S & $50.7 c$ & Charcoal & $820 \pm 30$ & -25 & M3 \\
\hline EL3EW-03 & 163380 & 3 & $\mathrm{E}$ & 60.1 & Charcoal & $590 \pm 80$ & -25 & 03 \\
\hline EL4.2S-05 & 166877 & $4 b$ & $S$ & 60.2 & Charcoal & $965 \pm 50$ & -25 & 05 \\
\hline EL4.2W-06 & 166878 & $4 b$ & W & $60.1-8$ & Charcoal & $790 \pm 25$ & -24.5 & $06 a$ \\
\hline EL3WW-06 & 163378 & 3 & W & 90 or $100 ?$ & Charcoal & $1740 \pm 20$ & -24.0 & $06 b$ \\
\hline EL4.2W-10 & 169917 & $4 b$ & W & $60.1-8$ & Charcoal & $920 \pm 35$ & -25 & $9-12$ \\
\hline EL4.2W-12 & 169918 & $4 b$ & W & $60.1-8$ & Charcoal & $865 \pm 30$ & -25 & $9-12$ \\
\hline EL4.2S-13 & 166882 & $4 b$ & $S$ & $50.7 c$ & Bulk soil + charcoal & $820 \pm 35$ & -25 & 13 \\
\hline EL4.2S-14 & 169919 & $4 b$ & $S$ & $50.7 c$ & Charcoal & $1470 \pm 60$ & -25 & 14 \\
\hline EL4.2S-15 & 166883 & $4 b$ & $S$ & $50.7 c$ & Charcoal & $625 \pm 25$ & -26.2 & 15 \\
\hline EL4-16 & 163000 & 4 & W & Unknown & Charcoal & $1540 \pm 25$ & -22.6 & $\mathrm{n} / \mathrm{a}$ \\
\hline EL4.2S-28 & 166896 & $4 b$ & $S$ & 45.2 & Charcoal & $180 \pm 70$ & -22.6 & 28 \\
\hline EL4-29 & 162997 & 4 & W & 60.3 & Charcoal & $890 \pm 20$ & -27.6 & 29 \\
\hline EL4-31 & 162999 & 4 & W & $40-1$ & Charcoal & $190 \pm 25$ & -23.8 & 31 \\
\hline EL4-36 & 163001 & 4 & W & $45.2-2$ & Charcoal & $525 \pm 30$ & -25 & 36 \\
\hline EL4WW-37 & 163383 & 4 & W & $40-9$ & Charcoal & $80 \pm 30$ & -25 & 37 \\
\hline EL4.2E-43 & 169916 & $4 b$ & $E$ & 70 & Charcoal & $830 \pm 35$ & -25 & 43 \\
\hline EL9W-57 & 169921 & 9 & W & 50.4 & Charcoal & $105 \pm 30$ & -25 & 57 \\
\hline EL9W-59 & 166888 & 9 & W & 50.3 & Charcoal & $230 \pm 40$ & -25 & 59 \\
\hline EL9W-60 & 166890 & 9 & W & 50.3 & Charcoal & $200 \pm 25$ & -24.6 & 60 \\
\hline EL9W-61 & 166891 & 9 & W & 50.2 & Charcoal & $350 \pm 30$ & -25 & 61 \\
\hline EL9W-62 & 169922 & 9 & W & 50.4 & Charcoal & $405 \pm 30$ & -25 & 62 \\
\hline EL9W-64 & 166895 & 9 & W & 45.3 & Charcoal & $410 \pm 110$ & -25 & 64 \\
\hline EL9W-65 & 166894 & 9 & W & 45.3 & Charcoal & $660 \pm 40$ & -25 & 65 \\
\hline EL9W-66 & 166897 & 9 & W & 45.2 & Charcoal & $140 \pm 30$ & -25.9 & 66 \\
\hline EL9E-71 & 166889 & 9 & $\mathrm{E}$ & 50.2 & Charcoal & $180 \pm 25$ & -23.7 & 71 \\
\hline EL9E-73 & 166887 & 9 & $E$ & $50.3-2$ & Charcoal & $185 \pm 25$ & -24.7 & 73 \\
\hline EL9E-74 & 166886 & 9 & $E$ & $50.4-9$ & Charcoal & $360 \pm 25$ & -24.6 & 74 \\
\hline EL9E-75 & 169953 & 9 & $E$ & $50.7 c$ & Charcoal & $1110 \pm 40$ & -25 & 75 \\
\hline EL9E-77A & 174849 & 9 & E & $50.5-9$ & Plant remains & $420 \pm 30$ & -28.2 & 77 \\
\hline EL9E-78 & 166884 & 9 & $E$ & $50.7 c$ & Charcoal & $885 \pm 35$ & -25 & 78 \\
\hline EL9E-79 & 169920 & 9 & $E$ & $50.7 b-1$ & Charcoal & $1010 \pm 45$ & -25 & 79 \\
\hline EL9E-81 & 166880 & 9 & E & $50.7 c$ & Charcoal & $735 \pm 30$ & -25.5 & 81 \\
\hline EL9E-83 & 166881 & 9 & E & $50.7 c$ & Charcoal & $925 \pm 40$ & -25 & 83 \\
\hline
\end{tabular}




\begin{tabular}{|c|c|c|c|c|c|c|c|c|}
\hline Sample Name & CAMS Lab ID & Trench & Wall & Unit* & Sample Type & ${ }^{14} \mathrm{C}$ age $(\mathrm{yr} \text { B.P. at } 1 \sigma)^{\dagger}$ & $\delta^{13} C^{\ddagger}$ & Trench Log Code \\
\hline EL3-100 & 162996 & 3 & W & Undiff. & Bulk sediment & $1750 \pm 40$ & -25 & 100 \\
\hline EL5WW-101 & 163393 & 5 & W & $90-8$ & Charcoal & $1675 \pm 25$ & -24.2 & 101 \\
\hline EL5WW-104 & 163392 & 5 & W & $90-9$ & Bulk sediment & $1720 \pm 35$ & -25 & 104 \\
\hline EL5WW-124 & 163396 & 5 & W & 60.3 & Charcoal & $805 \pm 25$ & -27.4 & 124 \\
\hline EL5EW-144 & 163398 & 5 & $E$ & 60.2 & Charcoal & $530 \pm 45$ & -25 & 144 \\
\hline EL5WW-148 & 163397 & 5 & W & 60.2 & Charcoal & $735 \pm 35$ & -25 & 148 \\
\hline EL6WW-150 & 163384 & 6 & W & $120-8$ & Charcoal & $2380 \pm 25$ & -24.9 & 150 \\
\hline EL6WW-152 & 163385 & 6 & W & $120-5$ & Charcoal & $2415 \pm 30$ & -24.7 & 152 \\
\hline EL5EW-167 & 163391 & 5 & $E$ & $100-1$ & Charcoal & $1720 \pm 35$ & -25 & 167 \\
\hline EL6WW-179 & 163387 & 6 & W & $110-1$ & Charcoal & $2040 \pm 25$ & -25.3 & 179 \\
\hline
\end{tabular}

Undiff., sample from stratigraphy where we were unable to confidently correlate units to known stratigraphy; n/a, not applicable; sample not labeled on trench logs. *Numbers following the hyphen (-) indicate relative position within unit. $1=$ upper contact to $9=$ basal contact.

${ }^{\dagger}$ Radiocarbon years using Libby half-life of $5568 \mathrm{yr}$ and following conventions of Stuiver and Polach (1977).

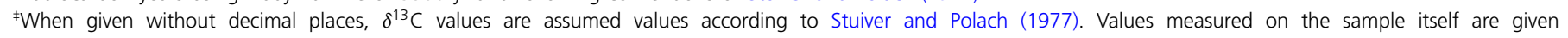
with a single decimal place.

being of high quality. T9W exhibits a consistent pattern of a downdropped and tilted unit 50.7, but most of the apparent causative faults are also associated with EL2, and it is unclear if these overprint older structures are associated with EL3 (Fig. S1). The limited occurrences of evidence for EL3 are likely a result of limited observation of the expanded stratigraphic section of unit 50, which is restricted to the eastern edge of our field site-only appearing in T9 and T4b (Figs. 4 and 5).

\section{Event 4-EL4}

Evidence for EL4 appears as faulting in T4b and T4E that offsets the finer-grained basal unit 60.3 and terminates within the coarsegrained sand to pebbly sand unit 60.2 (evidence occurs near meters 2.5 and 3.5 in Fig. 5, and between meters 2 and 3 in Fig. S7). Where preserved, unit 60.1 appears to not be offset by these faults. Unit 60.2 also changes thickness across these faults, suggesting it filled an irregular ground surface and then was juxtaposed by lateral separations. Unit 60.1 does not show this variation (Fig. 5).

In T6, thickness changes of unit 60 gives the appearance of sediment that filled a broad trough (between meters 6 and 10 in Figs. S12 and S13). If this trough predated the deposition of unit 60, it would record an event prior to EL4. However, the basal horizon of unit 60 in T6 does not change thickness across the trough, suggesting that it may have been deposited prior to creation of the trough, placing this deformation at a stratigraphic level consistent with the other evidence for EL4. Similar evidence is not present in T5, or the evidence has been overprinted by smaller-scale folding associated with EL2, EL3, and/or ELx.

\section{Event $\mathrm{x}$-ELX}

A distinctive stratigraphic feature within unit 50 persists across T3, T4W, T4E ext, T4b, and T9, located at meter 0 in each of these trenches (Figs. 4, 5, Figs. S1, S4-S6, and S8). This feature consists of thin $(0.2-2 \mathrm{~cm})$ laminae of clean fine-grained sand interbedded with clayey silt, forming a unique $0.5-0.8 \mathrm{~m}$ wide trough-shaped feature. This feature occurs between meters 1 and 2 north of the main fault zone associated with EL1 and EL2, and the top of the feature is consistently within the middle to upper section of unit 50 . The base of the feature cuts across the lower portion of unit 50 and locally into the underlying unit 60.1. In all occurrences, fault traces occur next to and/ or below the trough-shaped feature, and none of these faults can be traced above unit 50 (e.g., Figs. 4 and 5). Because the feature is persistently on the north side of the pop-up, can be connected for $30 \mathrm{~m}$ along the fault zone, and is typically bounded by or just above vertical faulting, we interpret the feature as a narrow fissure formed some time during the deposition of unit 50. Unfortunately, unit 50 is relatively thin and massive north of the EL1 fault zone and the lack of internal stratigraphy prevents possible correlation with the other events identified within the expanded stratigraphy of unit 50 south of the EL1 fault zone (EL2 and EL3) based on stratigraphic relationships. Therefore, the event that produced this troughshaped feature could have occurred during EL2, EL3, or as an additional, separate earthquake during the deposition of unit 50 .

In detail, the stratigraphic position of this event evidence suggests that the earthquake occurred during deposition of the upper section of unit 50. Notably, we expect that the 
fine-scale layering within the trough is unlikely to be preserved through many ruptures and, especially, near the surface with active soil-forming processes and bioturbation. Trenches T5 and T6 do not contain similar evidence for ELx.

\section{EVALUATION OF RECORD COMPLETENESS}

Table 2 provides a description of each observed piece of evidence of ground deformation and the associated earthquake horizon. Earthquakes EL1-4 and ELx are qualified as probable-to-very likely to be paleoearthquakes following Scharer et al. (2007), in that each is characterized by clear structural and sedimentologic deformation that indicate faulting disturbed a paleoground surface, and subsequent deposition preserved that surface rupture. Within the stratigraphy, and outlined in Table 2, are a few horizons that are associated with weak or inconclusive evidence of ground deformation. We designate these as possible events, following arguments in Scharer et al. (2007), and describe the deformation in these intervals that may be of use to subsequent studies.

\section{Possible event-ELy}

Two lines of evidence from T9, labeled ELy in Table 2, Figure 4, and Figure S1, permit the interpretation of an earthquake between EL1 and EL2. On the east wall of T9 (Fig. 4), there is sufficient stratigraphic resolution within unit 50 to identify a fault that may truncate the base of unit 50.2 in meter 2. Units 50.150.2 thicken across the fault, resulting in a southward-tapering wedge of sediment that is capped by the unit 45.3 basal contact. A similar wedge of sediment appears on the west wall of $\mathrm{T} 9$, but this stratigraphy is not as clearly associated with a pre-EL1 fault trace (Fig. S1). Below the wedge of sediment on the west wall of T9 are two cryptic fault traces that appear to cut the base of 50.2 but do not exhibit vertical separation above unit 50.4. In the other trenches, several faults penetrate into the uppermost part of unit 50 (50.1-50.3), but the association of these faults with EL1 or another event is ambiguous. For example, T4 and T4b both exhibit faults that terminate within $10-15 \mathrm{~cm}$ of the 45.3 basal contact, but, due to the massive nature of unit 50 in those trenches, more precise constraints on the timing and stratigraphic relationships are not possible. Unfortunately, due to the massive nature of upper unit 50 , we are unable to differentiate the ELy evidence from the evidence for EL1 and ELx, leading to the possibility that the ELy evidence is actually part of an earthquake we have already documented.

\section{Additional possible event evidence}

Multiple weak lines of evidence exist in stratigraphy below unit 70 for earthquakes preceding EL4 (Table 2). Several fault traces exhibit upward terminations within unit 90 (near meter 8 in T5 and meter 7 in T6; Fig. 6; Figs. S10-S13); in T5 and T6 east, this deformation cannot be clearly distinguished from deformation of younger units, because the associated folding is similar through the base of unit 60.3 (i.e., EL4). In T6 west, however, the steeply south-dipping fault between meters 7 and 8 separates a two-fold thickness change in unit 90 that suggests substantial lateral slip that did not deform unit 80 , providing some discrete evidence for an earthquake. There is similar weak evidence of older events. For example, a single fault strand vertically offsets the base of unit 110 by $40 \mathrm{~cm}$ at meter 10 on the west wall of T5 (Fig. 6) and produces a lateral mismatch in the thickness of unit 110 across the fault. The interaction of this fault with the diffuse basal contact of unit 100 is unclear, but unit 100 gradually thickens to the north, suggesting some relative lowering of the ground surface is preserved. The basal contact of unit 90 is not deformed. Unfortunately, the basal contact of unit 110 is not exposed on the east wall of $\mathrm{T} 5$, and no faulting was documented, so we lack corroborating lines of evidence for this event.

\section{RADIOCARBON AGE CONTROL}

We collected samples of organic material from trenches T3, T4, T4b, T5, T6, and T9 (Table 2, sample locations shown on Figs. S1-S13). Individual samples were examined under a dissecting microscope to identify primary sample components and remove potential contaminants before chemical pretreatment. Four bulk-sediment samples were processed by PaleoResearch Institute to isolate and identify macrofloral components for additional dating targets. All samples were chemically pretreated at Lawrence Livermore National Laboratory Center for Accelerator Mass Spectrometry, with most undergoing standard acid-alkali-acid $(\mathrm{HCl}$ and $\mathrm{NaOH})$ washes. Several small or delicate samples (noted on Table 3) were pretreated with only $\mathrm{HCl}$, to avoid possible sample destruction. Of 73 total samples, 35 were large enough to provide a split for $\delta^{13} \mathrm{C}$ measurement. Sample ages are calibrated to the IntCal 13 curve (Reimer et al., 2013) with OxCal 4.3 (Bronk Ramsey, 2009) with ages at $2 \sigma$ (95\% confidence limits) and reported as calendar years C.E./B.C.E. (Table 3).

\section{EARTHQUAKE AGES}

We modeled the age ranges for paleoearthquakes at the Elizabeth Lake site, using Bayesian methods implemented through the OxCal 4.3 sequence model framework (Bronk Ramsey, 2008; Lienkaemper and Bronk Ramsey, 2009). This method incorporates individual sample ages and uncertainties with a priori observations regarding stratigraphic order and unit boundaries, to model statistically robust age ranges for events within the model. Figure $7 \mathrm{a}$ provides the age range of 57 dated samples from $\mathrm{T} 3, \mathrm{~T} 4, \mathrm{~T} 4 \mathrm{~b}$, and $\mathrm{T} 9$ in stratigraphic order. As is common for sequences dated with detrital charcoal, in several layers (e.g., 45.2, 50.7c) there is an $\sim 400 \mathrm{yr}$ spread in the ages of individual samples. Furthermore, samples in different layers have overlapping probability distribution functions (PDFs) that make assessing the representativeness of their sample ages more difficult. To address issues of inheritance in modeling earthquake age ranges, we iteratively removed the oldest samples from each layer, until an agreement 


\begin{tabular}{|c|c|c|c|c|c|c|}
\hline EL1 & T4W & $0-0.5$ & 45.1 & 45.2 & 3 & $\begin{array}{l}\text { Units } 45.3 \text { and } 45.2 \text { truncated across tip of fault and absent on upthrown } \\
\text { side within } \sim 2 \mathrm{~m} \text { of the fault. On the downthrown side, } 45.3 \text { maintains } \\
\text { thickness, whereas, } 45.2 \text { is substantially thicker. Unit } 45.1 \text { is continuous } \\
\text { across fault projection, thickening slightly across the swale formed over the } \\
\text { downthrown side of the fault. }\end{array}$ \\
\hline EL1 & $\mathrm{T} 4 \mathrm{~b}$ & -1 to 5 & 45.3 & 45.2 & 3 & $\begin{array}{l}\text { Unit } 45.1 \text { appears broadly folded, but does not exhibit substantive unit } \\
\text { thickness change throughout the trench. Units } 45.2 \text { and } 45.3 \text { exhibit } \\
\text { similar broad folding to unit } 45.1 \text {, but only } 45.2 \text { exhibits a significant } \\
\text { thickness change across the fault zone. However, the basal contact of } 45.1 \\
\text { appears more gently folded than the underlying contacts, suggesting that } \\
\text { folding occurred prior to that unit. The contacts of } 45.3 \text { are parallel folded, } \\
\text { suggesting that folding occurred after this unit. }\end{array}$ \\
\hline EL1 & T9E & $1-1.4$ & 40 & 45.2 & 1 & $\begin{array}{l}\text { Thickness changes across the pop-up may reflect ground deformation event } \\
\text { (s) between units } 45.3 \text { and the lower portion of unit } 40 \text {. The greatest } \\
\text { thickness change appears to occur during unit } 45.2 \text {, which doubles in } \\
\text { thickness compared to the south side of the pop-up. However, the } 45.1 / 40 \\
\text { contact becomes quite diffuse here, so some additional thickening may occur } \\
\text { as late as the base of unit } 40 \text {. }\end{array}$ \\
\hline EL1 & T9W & $1-1.4$ & 40 & 45.2 & 2 & $\begin{array}{l}\text { Unit } 45.3 \text { is truncated at the fault zone on the north side of the pop-up and } \\
\text { absent across crest of pop-up. The basal contact of unit } 45.2 \text { does not } \\
\text { appear significantly offset where } 45.3 \text { is truncated; however, given the } \\
\text { absence of } 45.3 \text { on one side, the basal contact of } 45.2 \text { is likely older north } \\
\text { of the fault. The basal contact of } 45.1 \text { is diffuse, thus does not provide a } \\
\text { robust marker for limiting the upward termination of the fault. }\end{array}$ \\
\hline EL1 & T9W & $0-5$ & 45.2 & 45.1 & 1 & $\begin{array}{l}\text { On the south side of the fault-cored pop-up structure, unit } 45.3 \text { pinches } \\
\text { out toward the crest of the pop-up, appearing to be truncated by the basal } \\
\text { contact of } 45.2 \text {. Unit } 45.2 \text { also thins across the pop-up structure and } \\
\text { thickens significantly on the north side of the pop-up, with a sandier } \\
\text { interval in the middle of the unit. Unit } 45.1 \text { is bioturbated across the crest of } \\
\text { the pop-up, but the basal contact is weakly defined by the transition from } \\
\text { sand dominated above and organic-rich silt dominated below. This contact } \\
\text { becomes more diffuse north of the pop-up, limiting the clarity of the } \\
\text { structural and stratigraphic relationships. }\end{array}$ \\
\hline EL1 & T9W & 1 & 45.2 & 45.1 & 0 & $\begin{array}{l}\text { No discrete fault trace reaches the basal contact of } 45.3 \text {. However, due to } \\
\text { offsets, warping, and erosion of } 45.3 \text { corresponding with underlying faults, } \\
\text { the lack of discrete faulting is likely due to healing of fault traces in a clayey, } \\
\text { organic-rich soil and/or ductile warping of the ground surface. }\end{array}$ \\
\hline
\end{tabular}




\begin{tabular}{|c|c|c|c|c|c|c|}
\hline Event & Trench & $\begin{array}{l}\text { Trench } \\
\text { Location* }\end{array}$ & $\begin{array}{l}\text { Oldest } \\
\text { Unaffected Unit }\end{array}$ & $\begin{array}{l}\text { Youngest } \\
\text { Affected Unit }\end{array}$ & Quality $^{\dagger}$ & Evidence \\
\hline ELy & T9E & $2-3.5$ & 50.2 & 45.2 & 0 & $\begin{array}{l}\text { Within meters } 2 \text { to } 3 \text {, a north-dipping fault appears to truncate unit 50.2; } \\
\text { the upper extent is difficult to define and may extend into unit } 45.3 \text {. South } \\
\text { of the fault, a gentle wedge shape is apparent between the flat-lying unit } \\
50.2 \text { and the gently south-dipping } 45.3 \text { above. It is unclear if the dip of } \\
45.3 \text { is due to faulting during the deposition of } 45.2 \text { (EL1) or if } \\
\text { displacement during } 50.1 \text { created the south-dipping wedge surface on } \\
\text { which unit } 45.3 \text { subsequently onlapped. Relationships north of the pop-up } \\
\text { do not clarify this relationship. }\end{array}$ \\
\hline ELy & T9W & $2.4-2.6$ & 45.3 & 50.2 & 1 & $\begin{array}{l}\text { Two cryptic fault traces appear to cut the basal contact of unit } 50.2 \text { and } \\
\text { lower, but these faults only exhibit vertical unit offsets below } 50.4 \text {. The } \\
\text { upward terminations of these faults are not well expressed in the organic } \\
\text { and clay-rich units } 50.2 \text { and } 50.1 \text {, but unit } 45.3 \text { is not present north of } \\
\text { these faults until the depression north of the pop-up structure. It is possible } \\
\text { that these faults moved prior to deposition of } 45.3 \text { and that unit onlaps a } \\
\text { scarp, or the faults may have moved later (in EL1), and erosion across the } \\
\text { top of the pop-up produced the stratigraphic relationships. }\end{array}$ \\
\hline EL1(?) & T6E & -1 to 2 & Undiff. & Undiff. & 0 & $\begin{array}{l}\text { Faults approach surface through undifferentiated, organic-rich sediments } \\
\text { near base of geomorphic scarp. A wedge-shaped deposit of pebbly } \\
\text { colluvium extends downslope from the fault zone and is buried by deposits } \\
\text { at the same stratigraphic level as unit } 45 \text {. }\end{array}$ \\
\hline EL1(?) & T6W & -1 to 2 & Undiff. & Undiff. & 0 & $\begin{array}{l}\text { Faults approach surface through undifferentiated, organic-rich sediments } \\
\text { near base of geomorphic scarp. A wedge-shaped deposit of pebbly } \\
\text { colluvium extends downslope from the fault zone and is buried by deposits } \\
\text { at the same stratigraphic level as unit } 45 \text {. }\end{array}$ \\
\hline EL1(?) & T5E & $0-1$ & Undiff. & Undiff. & 0 & $\begin{array}{l}\text { Fault zone juxtaposes sheared gravel against sheared bedrock, fault is clear } \\
\text { to within } 40 \mathrm{~cm} \text { of ground surface, but the stratigraphy in this zone is } \\
\text { uncorrelated with documented units. }\end{array}$ \\
\hline EL2 & T9E & $2-4$ & 50.4 & 50.6 & 1 & $\begin{array}{l}\text { Minor, broad folding of basal unit } 50.5 \text { and below, that is not expressed in } \\
\text { the top of } 50.4 \text {, suggests deformation in the main fault zone between units } \\
50.6 \text { and } 50.4 \text {. }\end{array}$ \\
\hline EL2 & T9E & $2-3$ & 50.4 & 50.6 & 0 & $\begin{array}{l}\text { A single fault juxtaposes unit } 60 \text { against unit } 50.6 \text { (north side up). The } \\
\text { upper termination of this fault is not clear due to massive stratigraphy and a } \\
\text { younger, cross-cutting fault. }\end{array}$ \\
\hline EL2 & T9W & $2-4$ & 50.4 & 50.7 & 1 & $\begin{array}{l}\text { Units } 50.4-50.7 \text { double in thickness across a series of faults. Shearing } \\
\text { makes the exact stratigraphic location of the thinning difficult to identify, } \\
\text { but most of the faults appear to extend through unit } 50.7 \text { c. Faulting could } \\
\text { be during the deposition of } 50.7 \text { or later and capped by } 50.4 \text {. }\end{array}$ \\
\hline EL3 & T9E & $2-4$ & $50.7 a$ & $50.7 c$ & 4 & $\begin{array}{l}\text { Unit } 50.7 \mathrm{c} \text { and older are downdropped about } 50 \mathrm{~cm} \text { across a series of } \\
\text { faults. The top of unit } 50.7 \mathrm{a} \text { is not faulted. Overall, } 50.7 \text { thins toward the } \\
\text { main fault zone, suggesting the ground surface was deformed during the } \\
\text { deposition of } 50.7 \text {, likely within } 50.7 \mathrm{~b} \text { or } 50.7 \mathrm{a} \text {. }\end{array}$ \\
\hline EL3 & $\mathrm{T} 4 \mathrm{~b}$ & $4-5.3$ & $50.7 a$ & $50.7 c$ & 4 & $\begin{array}{l}\text { From fault at meter } 3.8 \text { to the south, unit } 50.7 \mathrm{c} \text { and } 60.1 \text { are tilted to the } \\
\text { southeast (also seen in south wall of trench). They appear to be partially } \\
\text { eroded where upthrown. Unit } 50.7 \mathrm{~b} \text { and } 50.7 \mathrm{a} \text { thicken to southwest, } \\
\text { recording gradual filling of the trough formed when } 50.7 \mathrm{c} \text { was at the } \\
\text { ground surface or early in the deposition of unit } 50.7 \mathrm{~b} \text {. }\end{array}$ \\
\hline
\end{tabular}

(continued) 


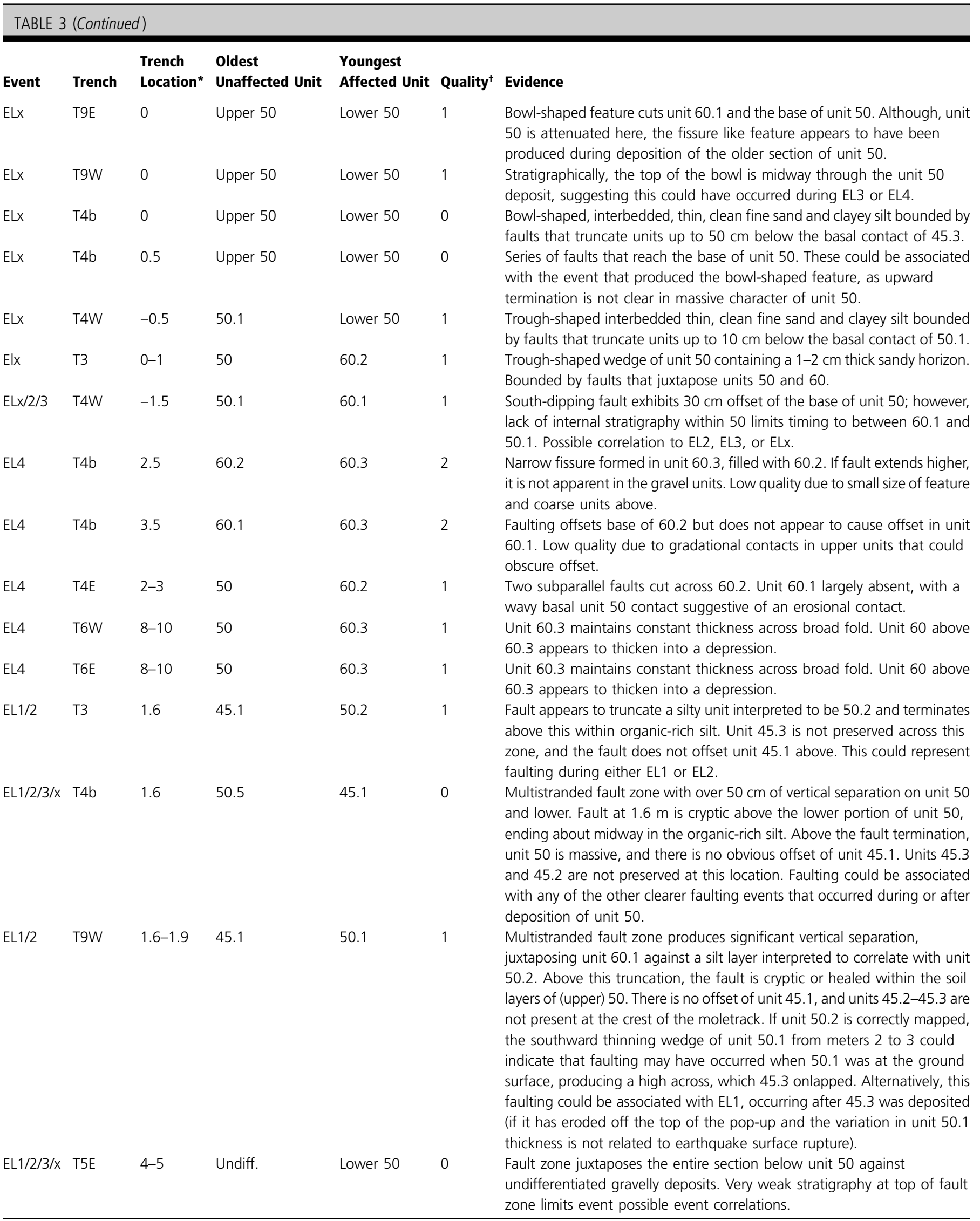




\begin{tabular}{|c|c|c|c|c|c|c|}
\hline Event & Trench & $\begin{array}{l}\text { Trench } \\
\text { Location* }\end{array}$ & $\begin{array}{l}\text { Oldest } \\
\text { Unaffected Unit }\end{array}$ & $\begin{array}{l}\text { Youngest } \\
\text { Affected Unit }\end{array}$ & Quality $^{\dagger}$ & Evidence \\
\hline $\mathrm{EL} 1 / 2 / 3 / \mathrm{x}$ & T5W & $4-5$ & Undiff. & Lower 50 & 0 & $\begin{array}{l}\text { Fault zone juxtaposes the entire section below unit } 50 \text { against } \\
\text { undifferentiated gravelly deposits. Very weak stratigraphy at top of fault } \\
\text { zone limits event possible event correlations. }\end{array}$ \\
\hline $\mathrm{EL} 1 / 2 / 3 / \mathrm{x}$ & T6E & $2.5-3.5$ & Undiff. & Undiff. & 0 & $\begin{array}{l}\text { Fault zone juxtaposes units } 60 \text { and below against older, undifferentiated } \\
\text { gravel deposits. Lack of internal stratigraphy above the fault zone restricts } \\
\text { more precise correlation of event evidence. }\end{array}$ \\
\hline $\mathrm{EL} 2 / 3 / \mathrm{x}$ & T9E & $0-1$ & 60 & Upper 50 & 0 & $\begin{array}{l}\text { Three faults cut through unit } 60 \text { and terminate within unit } 50 \text {. Unit } 50 \text { is } \\
\text { only } 10-30 \mathrm{~cm} \text { thick here and is limited to diffuse internal stratigraphy that } \\
\text { cannot be correlated to the subdivisions of unit } 50 \text { that occur south of the } \\
\text { fault zone in meter } 2 \text {. Thus, the stratigraphic position of this event between } \\
\text { EL1 and EL4 is unclear. }\end{array}$ \\
\hline$E L 2 / 3 / x$ & T9W & $0-1$ & 60 & Upper 50 & 0 & $\begin{array}{l}\text { Three faults cut through unit } 60 \text { and terminate within unit } 50 \text {. Unit } 50 \text { is } \\
\sim 40 \mathrm{~cm} \text { thick here and only contains weak internal stratigraphy that } \\
\text { cannot be correlated to the subdivisions of unit } 50 \text { that occur south of the } \\
\text { fault zone in meter } 2 \text {. However, compared to similar faults in T9E, these } \\
\text { faults appear to terminate lower within unit } 50 \text {. The stratigraphic position } \\
\text { of this event between EL1 and EL4 is unclear. }\end{array}$ \\
\hline $\mathrm{EL} 2 / 3 / \mathrm{x}$ & T5E & $6-11$ & 45 & 60.1 & 2 & $\begin{array}{l}\text { Unit } 60 \text { is folded between meters } 5 \text { and } 11 \text {. This deformation incorporates } \\
\text { portions of lower unit } 50 \text {. Unit } 45 \text { is horizontal and undeformed across the } \\
\text { deformed lower units. }\end{array}$ \\
\hline$E L 2 / 3 / x$ & T5W & $6-11$ & 45 & 60 & 2 & $\begin{array}{l}\text { Unit } 60 \text { is folded between meters } 5 \text { and } 11 \text {. This deformation incorporates } \\
\text { portions of lower unit } 50 \text {. Unit } 45 \text { is horizontal and undeformed across the } \\
\text { deformed lower units. }\end{array}$ \\
\hline
\end{tabular}

*Locations and intervals containing evidence are listed based on the horizontal grid distance (in meters) on the respective trench log.

${ }^{\dagger}$ Relative quality factor, estimated based on the clarity and ambiguity of the event evidence; $0=$ low clarity or high ambiguity, $5=$ clear features, unambiguous.

index of 50\% was achieved, slightly lower than recommended in Bronk Ramsey (2009). In general, soils and other finegrained deposits interpreted to have accumulated gradually are permitted to retain a broader range of sample ages than coarser-grained episodic deposits, which should be the best represented by the youngest ages. Ultimately, we retained 25 of 57 samples dated from T3, T4, T4b, and T9. We did not include the 15 samples from T5 and T6 in the earthquake age models, due to the potential uncertainty from correlating units between different portions of the site.

In the stratigraphy at Elizabeth Lake, some earthquake horizons are broadly constrained to an interval containing multiple dated units (e.g., EL3 in the interval defined by $50.7 \mathrm{a}, 50.7 \mathrm{~b}$, and $50.7 \mathrm{c}$ ). To assess the impact of different interpretations regarding the placement of earthquake timing between or within units, we developed two separate sequence models using the same 25 radiocarbon ages in each. The "traditional" model employs the common strategy of calculating earthquake ages, as if they are between two discrete layers that may contain multiple dated samples (i.e., phases; Lienkaemper and Bronk Ramsey, 2009). With this approach, EL1 is modeled as occurring between units 45.2 and 40 (1790-1890 C.E.), EL2 between units 50.5 and 50.4 (1450-1610 C.E.), EL3 within subunits of $50.7 \mathrm{c}(1310-1400$ C.E.), and EL4 between 60.3 and 60.1 (11701250 C.E.). The uncertainty on individual earthquake ages from this model (Table 4 ) has mean $2 \sigma$ ranges of $80-100 \mathrm{yr}$ (EL1, EL3, and EL4) and $160 \mathrm{yr}$ (EL2).

We developed another model (the modified model; Fig. 7b) that recognizes that the exact paleoground surface of EL3 and EL4 occurred within a set of dated layers, and that age ranges for sequential layers are often overlapping. In this model, instead of deriving an earthquake age from two bounding layers, the age of the earthquake is determined by the age of the layers that encompass the earthquake horizon. With this 
(a)

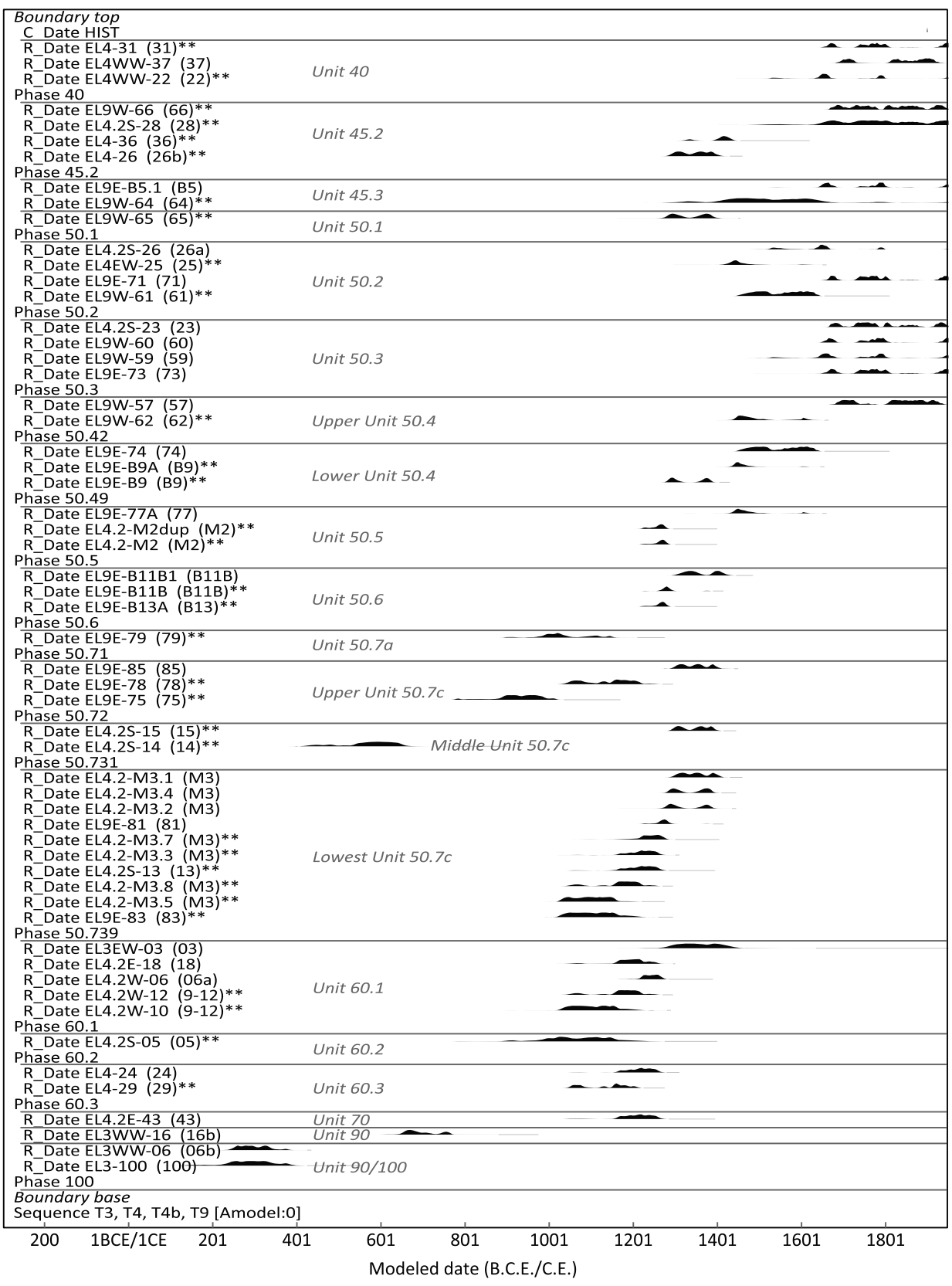

Figure 7. (a) Age plot of all calibrated radiocarbon dates from the southeastern trenches, T3, T4, T4b, and T9. The resulting radiocarbon ages document a significant detrital component to charcoal ages, with up to $400 \mathrm{yr}$ variability for samples from the same layer. Sample names denoted with a double asterisk are not included in the earthquake age models. (b) Our modified earthquake age model used to define earthquake ages (red probability distribution functions [PDFs]; Table 3). This model results from our recognition that the paleoground surfaces for ELx, EL3, and EL4 are not well constrained between individual units or by the radiocarbon dates within proximal units. We, therefore, model the earthquake age as spanning a unit or sequence of units. An alternate age model, using a traditional structure of constraining earthquakes between units or phases, is presented in Figure S14. Sequence models run in OxCal version 4.3.2 (Bronk Ramsey, 2017), using the IntCal13 atmospheric curve (Reimer et al., 2013). The color version of this figure is available only in the electronic edition.

(Continued)

contrast to the traditional model in which earthquake age ranges are bound by the youngest age in the unit that predates the earthquake and the oldest age in the unit that postdates the earthquake.

The differences between the traditional and modified earthquake age models appear in how the earthquake age ranges for EL3 and EL4 are derived. Specifically, for EL3, the postearthquake layer (upper unit 50.7c) and the stratigraphy does not definitively place the EL3 ground surface before or after the middle unit of $50.7 \mathrm{c}$. Recognizing this uncertainty, we model the earthquake age as spanning unit 50.7, allowing two samples from $50.7 \mathrm{~b}$ and the overlying unit 50.6 to contribute what we consider as a more representative stratigraphic uncertainty for EL3 of 150 yr (1260-1410 C.E.; Table 4). Similarly, we interpret EL4 as having occurred during deposition of unit 60.2 , but most of the samples from this unit and the bounding units (60.1 and 60.3) produced similar ages without a clear association of the younger deposits having younger ages. Unit 60 is coarse grained and likely records storm events that entrained sediment from the larger catchment. Strong overlap in the youngest samples from layers in unit 60 suggests that charcoal generated during a single fire event was incorporated in all of the unit 60 sublayers and that our samples did not capture the intermediate ages between the charcoal produced before the earthquake and the charcoal that occurs approach, we allow the earthquake age to be defined by multiple layers, reflecting our uncertainty in the exact stratigraphic location of the ground surface at the time of the earthquake, in in the overlying unit 50.7. We, therefore, model the age range of EL4 as spanning unit 60, allowing the timing of the earthquake to effectively be constrained by the suite of pre- 
(b)

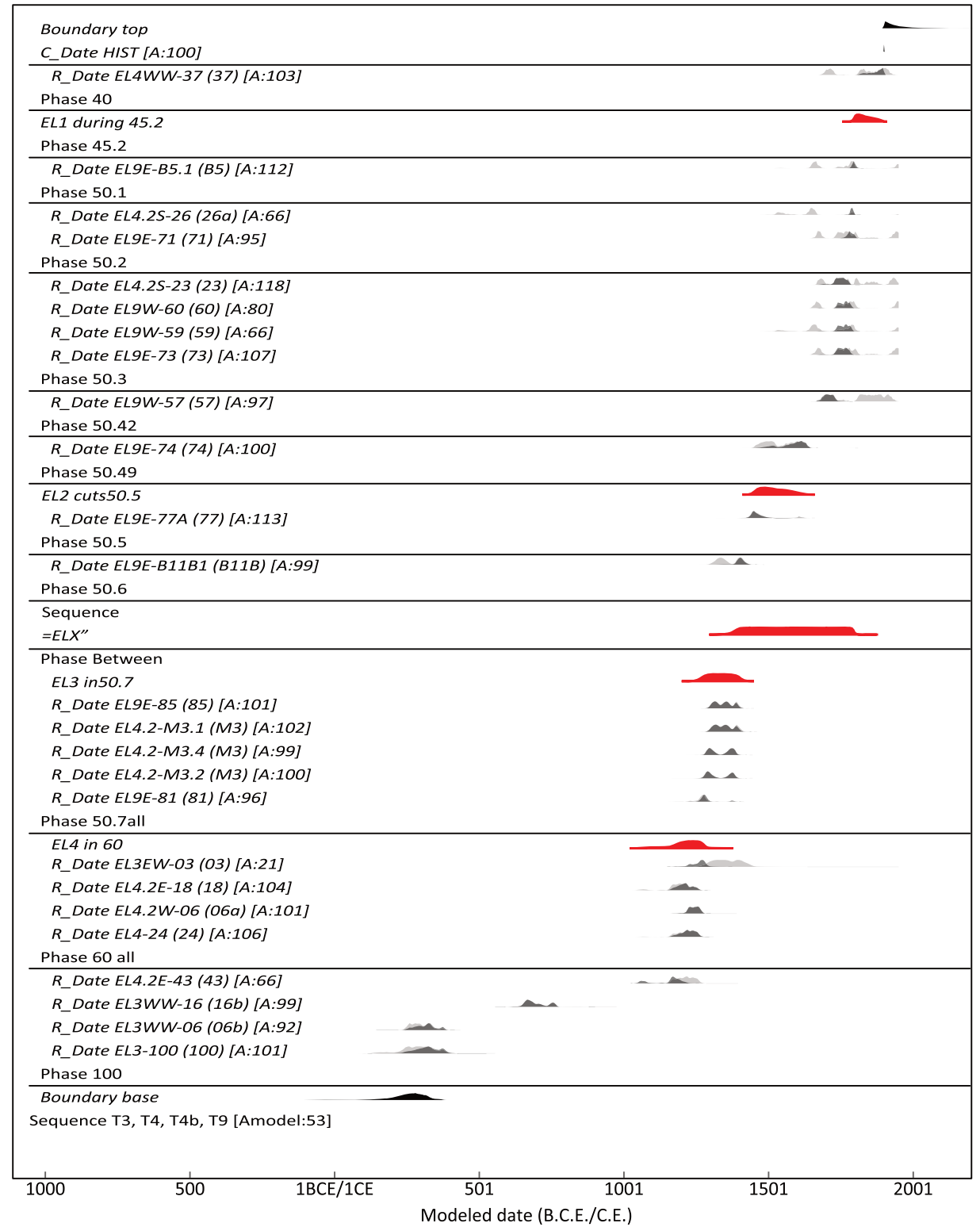

Figure 7. Continued earthquake charcoal within unit 60 and postearthquake charcoal that occurs in unit $50.7 \quad(1090-1290 \quad$ C.E.; Table 3). We retain the traditional model format for EL1 and EL2, because those earthquakes are the best constrained between units containing age control.

The mean earthquake ages for EL1 (1830) and EL2 (1520) are identical between the traditional and modified age models, because they use the same model constraints (Table 4). For EL3 and EL4, the mean earthquake ages vary by only 30 and 10 years, respectively (Table 4), despite the different age model structure. The important result from the different model structures is in the ranges of the earthquake ages, in which the traditional model provides age ranges that are narrower than the modified model ages by 60 and $120 \mathrm{yr}$ for EL3 and EL4, respectively. We argue that the traditional sequence model artificially narrows the EL3 and EL4 earthquake age ranges, and that our modified age model is more representative of the uncertainty inherent to the dating and stratigraphic uncertainty on likely earthquake timing.

Estimating an age for ELx provides a separate challenge, because the stratigraphic

\begin{tabular}{|c|c|c|c|c|c|c|}
\hline \multirow{2}{*}{$\begin{array}{l}\text { Event } \\
\text { EL1 }\end{array}$} & \multicolumn{3}{|c|}{ Modified Age Model (Calendar Years C.E.) } & \multicolumn{3}{|c|}{ Traditional Age Model (Calendar Years C.E.) } \\
\hline & \multicolumn{2}{|c|}{ 95\% Range } & $\begin{array}{c}\text { Mean } \\
1830\end{array}$ & \multicolumn{2}{|c|}{ 95\% Range } & $\begin{array}{l}\text { Mean } \\
1830\end{array}$ \\
\hline EL2 & 1450 & 1610 & 1520 & 1450 & 1610 & 1520 \\
\hline EL3 & 1260 & 1410 & 1330 & 1310 & 1400 & 1360 \\
\hline EL4 & 1090 & 1290 & 1220 & 1170 & 1250 & 1210 \\
\hline
\end{tabular}


(a)

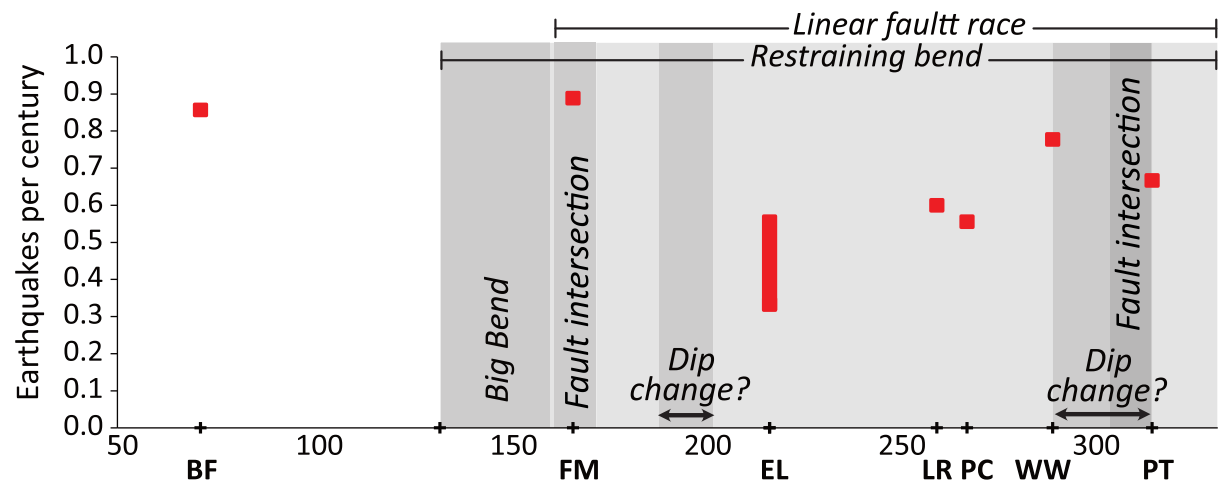

(b)

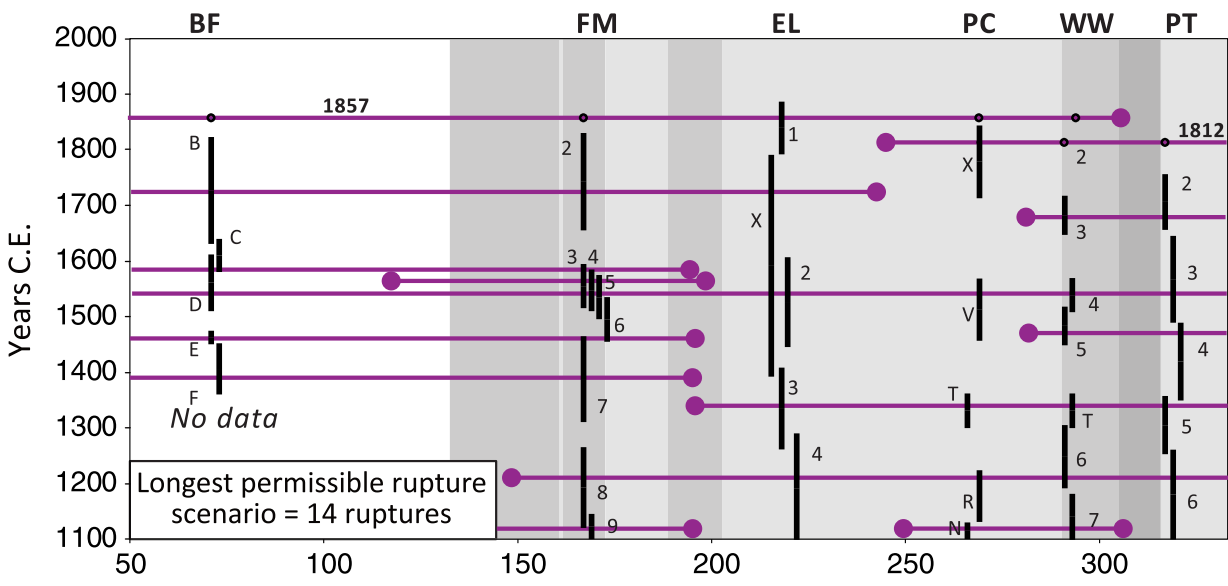

Figure 8. Examples of plausible earthquake scenarios for the SSAF. Vertical bars encompass $95 \%$ confidence bounds for earthquake age ranges at each paleoseismic site, labeled with corresponding site-specific event codes assigned by previous studies. Thin horizontal lines show plausible ruptures lengths for earthquakes based on correlations of contemporaneous earthquakes. Gray shaded fields highlight geometric complexities associated with the restraining bend; darker gray indicates more complexities operating in that zone. (a) Plot of earthquakes per century, calculated through 2000 C.E., for each paleoseismic site, illustrating how the frequency of earthquakes changes through the restraining bend. (b) This scenario correlates all contemporaneous earthquakes between adjacent sites, making earthquakes as long as permissible within the age constraints. In this version, we interpret that ELx occurred after EL2 and, thus, correlates with FM2. (c) Earthquake scenario assuming that the Fuis et al. (2012) fault dip changes are real and promote rupture termination. If ELX is the same event as EL2, as shown here, the number of ruptures spanning the Big Bend and Mojave south sections can be reduced. (d) An example scenario with no assumed controls on rupture endpoints and shorter ruptures are permitted. Rupture endpoints for (b) and (c) are placed halfway between paleoseismic sites, whereas, in (d) the endpoints are arbitrarily positioned between adjacent sites. Site names (and references): BF, Bidart Fan (Akçiz et al., 2010); EL, Elizabeth Lake (this study); FM, Frazier Mountain (Scharer et al., 2017); PC, Pallett Creek (Scharer et al., 2011); PT, Pitman Canyon (Seitz et al., 1997); LR, Littlerock; WW, Wrightwood (Weldon et al., 2004). Fault intersections: GF, Garlock fault; SJF, San Jacinto fault. The color version of this figure is available only in the electronic edition.

(Continued)
Furthermore, it is possible that the minor deformation discussed is the product of mechanisms other than direct surface rupture, such as minor triggered slip or differential settling. The stratigraphic position of the ELy possible event, just preceding evidence of 1857 (EL1) could be consistent with the 1812 Wrightwood earthquake that is recorded at paleoseismic sites to the southeast along the fault, or with a slightly older event recorded to the northwest (i.e., the penultimate earthquake at Frazier Mountain).

Notably, the ELy evidence is discernible only in the thickest sedimentary section exposed in any of our trenches, in which the accelerated sediment accumulation rate would be the most likely to record a separate event that occurred closely spaced in time to another event. The absence of evidence for ELy in our other trenches, therefore, does not necessarily mean that this event did not cause deformation in those trenches, but rather that it might not be discernible in areas where sediment accumulation was slower than in trench T9. In summary, the ELy deformation could record rupture of the 1812 earthquake, the penultimate Frazier Mountain earthquake, or it could correspond with EL1 or ELx. Alternatively, the appar- constraints on the timing of ELx cannot be unambiguously correlated to the dated stratigraphy south of the fault zone. Given the uncertainty in the ground surface at the time of ELx relative to the dated samples, both models permit that it could have occurred any time between layers 50.6 and 50.2 , inclusive. As a result, the age range of ELx is long; it overlaps slightly with EL3 and encompasses the full range of EL2 (Table 4).

The possible event, ELy, is not included in the age model framework, because the evidence for this event is weak. ent ELy offset and sedimentation could have been the result of strong shaking from an earlier earthquake, such as, 1812, and it may not necessarily record surface rupture at this site. Until better age control (e.g., pollen or tree ring evidence) and additional deformation evidence can be found, the northern extent of the 1812 rupture remains unclear.

\section{RUPTURES ON THE MOJAVE SECTIONS OF THE SAF}

The earthquake chronology at Elizabeth Lake provides evidence of four or, possibly, five surface ruptures of the SAF since 
(c)

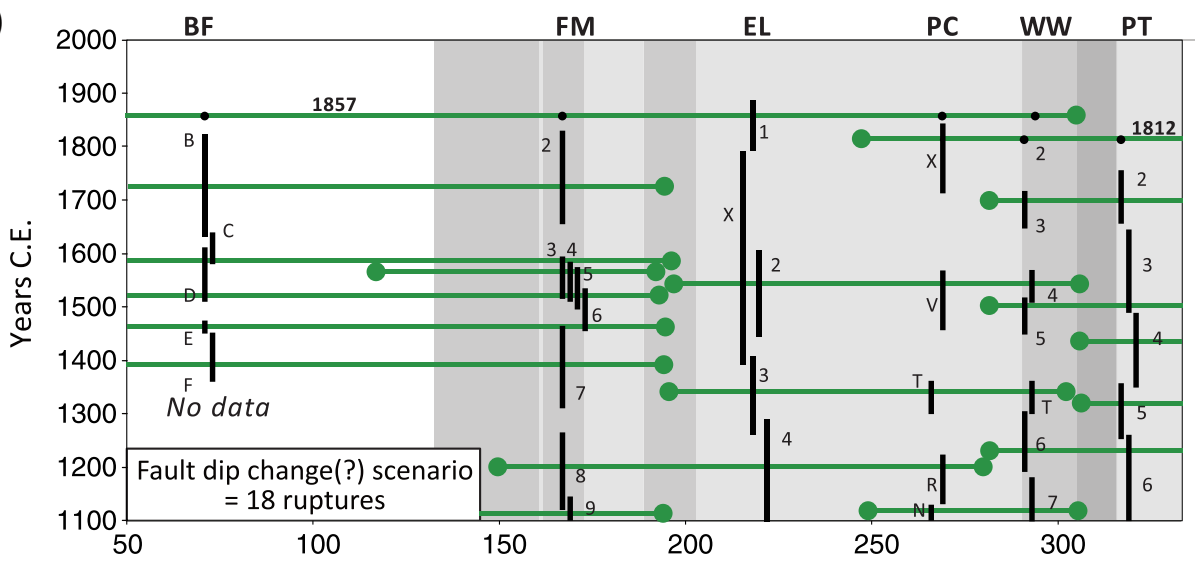

(d)

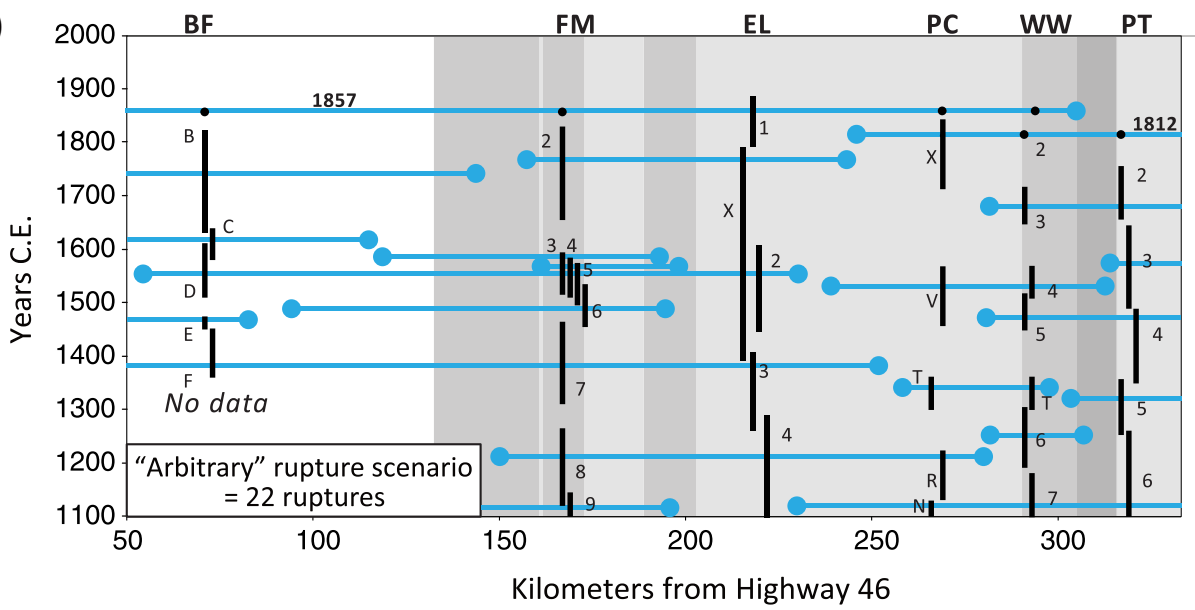

Figure 8. Continued complexities-the restraining bend, fault intersections, and changes in fault dip-allows us to examine which of these factors play roles in terminating rupture.

If long, large-magnitude earthquakes typify the SSAF, then we can build a model in which earthquakes correlate between sites if their ages are contemporaneous. Building off of the model in Scharer et al. (2017), Figure $8 \mathrm{~b}$ provides one of several possible variations of this end-member scenario, in which we only terminate a rupture if there is no earthquake with an overlapping age range at the next adjacent paleoseismic site. For simplicity, ruptures are assumed to terminate half-way between noncorrelating sites. Ambiguity about the timing of ELx relative to EL2 creates different correlation options, depending on whether ELx is the same event as EL2, or if it is a separate event that occurred before or after. We illustrate ELx as occurring as a separate event after EL2 in Figure $8 \mathrm{~b}$ on the basis that the fine-scale laminations preserved as stratigraphic evidence for ELx would not survive a significant amount of time within a few decimeters of the surface in a marsh environment. The longest permissible ruptures include the 1857 earthquake, a rupture in the mid-1500s that extends from Bidart Fan to Pitman Canyon, and a rupture from, at least, Frazier Mountain to Pitman Canyon near 1200 C.E. In this model, Wrightwood and Pitman Canyon typically rupture together, with some ruptures extending to include additional sites to the northwest. Similarly, of the six ruptures that connect the Carrizo and the Big Bend sections, since 1300 C.E., only two extend across the Mojave south section at Elizabeth Lake. The five rupture terminations between Frazier Mountain and Elizabeth Lake could be attributed to the Big Bend, the intersection with the Garlock fault, or the proposed change in dip of the SAF (Fuis et al., 2012).

We develop another scenario in which we impose rupture endpoints that correspond with the zones of fault intersections and modeled subsurface fault dip changes of Fuis et al. (2012), assuming that these features exert a strong influence on 
the propagation of ruptures along the SSAF. This scenario increases the total number of earthquakes and shortens average rupture lengths (Fig. 8c). The difference in the number of earthquakes between Frazier Mountain and Elizabeth Lake requires at least four rupture endpoints to occur between these sites, and, in this model, we infer the ELx and EL2 are the same earthquake, increasing this difference to five. Superposition constraints due to the close timing of earthquakes 3-6 at Frazier Mountain require an additional termination between Frazier Mountain and Elizbeth Lake. We create two additional endpoints in this zone by splitting the long rupture near 1550 C.E. in Figure $8 \mathrm{~b}$ into two separate ruptures, leaving just one additional earthquake (about 1200 C.E.) besides 1857 to propagate across the proposed fault dip change. The southeastern dip change encompasses the location of the Wrightwood site, permitting rupture endpoints to occur either northwest or southeast of Wrightwood while being consistent with the zone of a fault dip change. This scenario requires that more ruptures have endpoints to the northwest of Wrightwood, because of the difference in the number of recorded earthquakes between Wrightwood (eight earthquakes) versus Pallett Creek (six earthquakes) (Fig. 8c). Compared to the maximum rupture length model of Figure $8 \mathrm{~b}$, Figure $8 \mathrm{c}$ shows that the paleoearthquake ages can be consistent with a model in which subsurface changes in fault dip control the extent of earthquakes.

A model in which each paleoearthquake represents a single event would produce over 30 ruptures in $\sim 700 \mathrm{yr}$, producing a recurrence rate that we consider to be unrealistic, given the historical record. Consequently, our third correlation scenario (Fig. 8d) chooses arbitrary endpoints and does not assume a priori that geometric changes play a role. This scenario illustrates that some earthquakes can rupture a single paleoseismic site, but more often multiple sites are ruptured (Fig. 8d). There are many permutations of this scenario due to fewer assumptions constraining earthquake correlations; however, differences in the number of recorded earthquakes at individual sites force all scenarios to contain a minimum number of four ruptures at Frazier Mountain that terminate before reaching Elizabeth Lake.

Between all possible rupture scenarios, the fault geometry and the number of earthquakes per site remain unchanged (except for decisions on treating ELx as the same as EL2 or a separate event). What becomes apparent is that sites with more earthquakes since 1100 C.E. are located near major fault bends and intersections with other major active faults (Garlock fault, San Jacinto fault). Conversely, the sites with fewer earthquakes (Elizabeth Lake and Pallett Creek) occupy the central portion of a relatively straight section of the SAF. Sites outside the central portion have similar records. For example, the apparent cluster of earthquakes 3-6 at Frazier Mountain contains only one earthquake that cannot be correlated to earthquakes at the Bidart Fan site (e.g., Fig. 8b), leaving Frazier
Mountain and Bidart Fan with seven and six earthquakes since $\sim 1300$ C.E., respectively. The rate at Wrightwood is slightly higher than neighboring sites, which may be attributed to interaction with the San Jacinto fault (e.g., Weldon et al., 2004; Lozos, 2016; Scharer and Yule, 2020). Along-fault earthquake frequency and earthquake correlation scenarios (Fig. 8) - demonstrate that greater fault geometric complexity corresponds with where earthquakes are more frequent, in this case, where the fault bends and intersects with other major active faults. Our new paleoearthquake data from Elizabeth Lake do not discriminate which of the scenarios for earthquake ruptures on the SSAF is the most accurate. However, these scenarios illustrate how the lower number of earthquakes on the Mojave south section (Elizabeth Lake and Pallett Creek) requires that multiple rupture endpoints occur near the fault geometry changes at the ends of this fault section, regardless of specific earthquake behavior assumptions.

Several studies have examined how Coulomb stress changes are imparted at the major fault intersections in Figure 8a. At the Garlock intersection with the SAF, two studies have argued that Coulomb stress changes from an earthquake near the Garlock fault could trigger rupture of the Garlock fault, which, in turn, could trigger rupture of the Mojave sections of the SAF (McAuliffe et al., 2013; Toda and Stein, 2020). Coulomb models of the SAF show that 1857-like events reduce stress on the Garlock (Lin and Stein, 2004). Events EL2 and ELx at Elizabeth Lake have a similar age to the cluster of events at Frazier Mountain and a rupture on the Garlock fault, which McAuliffe et al. (2013) propose, could be a series of triggered events about 1450-1550 C.E. Although, $100 \mathrm{yr}$ uncertainties in ages of paleoearthquakes cannot demonstrate potential triggering mechanisms between closely timed earthquakes, the record shows that syncopation of Garlock and SAF earthquakes is not a common mode of rupture, given the longer recurrence interval of Garlock fault earthquakes (e.g., Madugo et al., 2012) and the lower frequency of earthquakes on the Mojave south section of the SAF compared to the Big Bend.

The 1857 Fort Tejon earthquake ruptured through the Big Bend of the SAF and continued through the oblique restraining section to the southeast for $\sim 150 \mathrm{~km}$. In contrast, the 1812 Wrightwood earthquake and lower surface-rupture frequencies for paleoseismic sites on the Mojave sections of the SAF indicate that these throughgoing ruptures are not typical. Dynamic rupture modeling with multicycle effects (Duan and Oglesby, 2005) and complex 3D fault structure (Douilly et al., 2020) show that earthquake ruptures that encounter a bend in a strike-slip fault can continue through the bend, but often terminate within a short distance past it. Furthermore, integrating the $3 \mathrm{D}$ fault geometry in the dynamic rupture models demonstrates the sensitivity of rupture propagation to small changes in fault geometry and pre-existing fault stress (Douilly et al., 2020). In the case of the Big Bend and Mojave sections of the 
SAF, this implies that either dynamic rupture processes drive ruptures through the Big Bend or, perhaps, a previously unmodeled effect, such as subsurface fault dip change, also contributes to terminating ruptures as they reach the Mojave sections. This study suggests that the fault geometry changes aid in terminating some ruptures, leading to a lower earthquake frequency for the Mojave south section of the fault and providing a specific behavior that can be used as a test on models of rupture propagation through the restraining bend.

\section{CONCLUSIONS}

Our studies document new paleoearthquake constraints from the Elizabeth Lake paleoseismic site on the SSAF. The most recent earthquake (EL1) is consistent with the 1857 Fort Tejon earthquake. The ages of the preceding surface ruptures-EL2 (1450-1610 C.E.), EL3 (1260-1410 C.E.), and EL4 (10901290 C.E.) - are well constrained within an expanded stratigraphic section at the southeasternmost edge of the study site. We also document an event we term "ELx" that may be a separate earthquake (1390-1790 C.E.) or another expression of EL2 deformation that we are unable to correlate across the primary fault zone. Along-fault correlation of the paleoearthquakes at Elizabeth Lake with chronologies from adjacent paleoseismic sites confirm the relative infrequency of 1857-sized ruptures and illustrate an abrupt change in the number of earthquakes recognized at paleoseismic sites through the SSAF over the past 900 yr. Elizabeth Lake and Pallett Creek record up to five and six earthquakes, respectively, on the linear, vertical portion of the SSAF. In contrast, the adjacent Frazier Mountain and Wrightwood sites, which are located on collinear but kinematically complex portions of the SAF, record eight or nine earthquakes. This pattern requires more frequent earthquakes that rupture through the Big Bend-Mojave north section and the San Bernardino north section than occur through the straight and vertical Mojave south section. Consequently, we suggest that the combined effect of greater plate motion obliquity, fault intersections, and possible fault dip changes exert a significant control on the initiation and/or propagation of SSAF earthquake ruptures, and that this effect may be more persistent than correlations of earthquake behavior with bends in the fault surface trace. This observation may improve the correlation between fault bends and the endpoints of strike-slip earthquakes documented by previous studies (e.g., Biasi and Wesnousky, 2017), such as, in this study, in which the proposed changes in fault dip at the ends of the Mojave south section (Fuis et al., 2012) are not evident in the fault surface trace but may be assisting to terminate ruptures. Dynamic rupture models will also be strongly influenced by these subsurface bends, but, will not be captured, if fault geometry is defined by surface trace alone.

\section{DATA AND RESOURCES}

All data used in this article came from published sources listed in the references or provided in the supplemental material. The supplemental material consist of (1) high-resolution photomosaics and logs from the paleoseismic trenches used in defining the stratigraphic and structural relations in this study, (2) code and output for our OxCal sequence model. The Santa Barbara earthquakes from 1855 to 1860 are available at https://projects.eri.ucsb.edu/sb_eqs/SBEQCatlog/SBEQdescrips/ SBEQs1855-1860.html (last accessed October 2020).

\section{DECLARATION OF COMPETING INTERESTS}

The authors acknowledge that there are no conflicts of interest recorded.

\section{ACKNOWLEDGMENTS}

This research was supported by the Southern California Earthquake Center (SCEC, Contribution Number 10887). SCEC is funded by the National Science Foundation (NSF) Cooperative Agreement EAR1600087 and U.S. Geological Survey (USGS) Cooperative Agreement Number G17AC00047. Additional thanks to SCEC for the use of community shores. Thanks to Ridgetop Ranch Properties for access to their property and Bob's Backhoe of Quartz Hill for excavation services. Field assistance provided by A. Hatem, R. Zinke, C. Milliner, R. Witkosky, C. Wespestad, J. Grenader, L. DeVore, T.P. Taylor, C. Burkett, A. Hislop, J. Lucas, and others. Comments by A. Hatem, C. DuRoss, and two anonymous reviewers improved this article. Our field efforts benefitted from the high-resolution topographic data derived from the B4 light detection and ranging (lidar) project.

Any use of trade, firm, or product names is for descriptive purposes only and does not imply endorsement by the U.S. Government.

\section{REFERENCES}

Acharya, H. K. (1997). Influence of fault bends on ruptures, Bull. Seismol. Soc. Am. 87, no. 6, 1691-1696.

Akçiz, S. O., L. G. Ludwig, J. R. Arrowsmith, and O. Zielke (2010). Century-long average time intervals between earthquake ruptures of the San Andreas fault in the Carrizo Plain, California, Geology 38, no. 9, 787-790, doi: 10.1130/G30995.1.

Barak, S., S. L. Klemperer, and J. F. Lawrence (2015). San Andreas Fault dip, Peninsular Ranges mafic lower crust and partial melt in the Salton Trough, Southern California, from ambient-noise tomography, Geochem. Geophys. Geosys. 16, no. 11, 3946-3972, doi: 10.1002/2015GC005970.

Barka, A. A., and K. Kadinsky-Cade (1988). Strike-slip fault geometry in Turkey and its influence on earthquake activity, Tectonics 7, no. 3, 663-684, doi: 10.1029/TC007i003p00663.

Bevis, M., and K. Hudnut (2005). Airborne Laser Swath Mapping (ALSM) survey of the San Andreas Fault (SAF) system of central and southern California, including the Banning segment of the SAF and the San Jacinto fault system, National Center for Airborne Laser Mapping (NCALM), U.S. Geological Survey, the Ohio State University, and the Southern California Integrated GPS Project, doi: 10.5066/F7TQ5ZQ6.

Biasi, G. P., and S. G. Wesnousky (2016). Steps and gaps in ground ruptures: Empirical bounds on rupture propagation, Bull. Seismol. Soc. Am. 106, no. 3, 1110-1124, doi: 10.1785/0120150175.

Biasi, G. P., and S. G. Wesnousky (2017). Bends and ends of surface ruptures, Bull. Seismol. Soc. Am. 107, no. 6, 2543-2560, doi: $10.1785 / 0120160292$. 
Bronk Ramsey, C. (2008). Deposition models for chronological records, Quaternary Sci. Rev. 27, nos. 1/2, 42-60, doi: 10.1016/ j.quascirev.2007.01.019.

Bronk Ramsey, C. (2009). Bayesian analysis of radiocarbon dates, Radiocarbon 51, no. 1, 337-360, doi: 10.1017/S0033822200033865.

Bronk Ramsey, C. (2017). OxCal program, Version 4.3, Oxford Radiocarbon Accelerator Unit, University of Oxford, available at https://c14.arch.ox.ac.uk/oxcal/OxCal.html (last accessed May 2020).

Douilly, R., D. D. Oglesby, M. L. Cooke, and J. L. Hatch (2020). Dynamic models of earthquake rupture along branch faults of the eastern San Gorgonio Pass region in California using complex fault structure, Geosphere 16, no. 2, 474-489, doi: 10.1130/ GES02192.1.

Duan, B., and D. D. Oglesby (2005). Multicycle dynamics of nonplanar strike-slip faults, J. Geophys. Res. 110, no. B3, B03304, doi: 10.1029/2004JB003298.

Elliott, A. J., J. F. Dolan, and D. D. Oglesby (2009). Evidence from coseismic slip gradients for dynamic control on rupture propagation and arrest through stepovers, J. Geophys. Res. 114, no. B2, B02313, doi: 10.1029/2008JB005969.

Elliott, A. J., M. E. Oskin, J. Liu, and Y. Shao (2015). Rupture termination at restraining bends: The last great earthquake on the Altyn Tagh fault, Geophys. Res. Lett. Article Number 2015GL063107, doi: 10.1002/2015GL063107.

Field, E. H., T. H. Jordan, M. T. Page, K. R. Milner, B. E. Shaw, T. E. Dawson, G. P. Biasi, T. Parsons, J. L. Hardebeck, A. J. Michael, et al. (2017). A synoptic view of the third Uniform California Earthquake Rupture Forecast (UCERF3), Seismol. Res. Lett. 88, no. 5, 1259-1267, doi: 10.1785/0220170045.

Forand, D., J. P. Evans, S. U. Janecke, and J. Jacobs (2018). Insights into fault processes and the geometry of the San Andreas fault system: Analysis of core from the deep drill hole at Cajon Pass, California, Geol. Soc. Am. Bull. 130, nos. 1/2, 64-92, doi: 10.1130/ B31681.1.

Fuis, G. S., D. S. Scheirer, V. E. Langenheim, and M. D. Kohler (2012). A new perspective on the geometry of the San Andreas fault in southern California and its relationship to lithospheric structure, Bull. Seismol. Soc. Am. 102, no. 1, 236-251, doi: 10.1785/ 0120110041.

Fumal, T. E., R. J. Weldon, G. P. Biasi, T. E. Dawson, G. G. Seitz, W. T. Frost, and D. P. Schwartz (2002). Evidence for large earthquakes on the San Andreas fault at the Wrightwood, California, paleoseismic site: A.D. 500 to Present, Bull. Seismol. Soc. Am. 92, no. 7, 2726-2760, doi: 10.1785/0120000608.

Hanks, T. C., and W. H. Bakun (2008). M-logA observations for recent large earthquakes, Bull. Seismol. Soc. Am. 98, no. 1, 490494, doi: 10.1785/0120070174.

Harris, R. A. (1998). Introduction to special section: Stress triggers, stress shadows, and implications for seismic hazard, J. Geophys. Res. 103, no. B10, 24,347-24,358, doi: 10.1029/98JB01576.

Jacoby, G. C., P. R. Sheppard, and K. E. Sieh (1988). Irregular recurrence of large earthquakes along the San Andreas fault: Evidence from trees, Science 241, no. 4862, 196-199, doi: 10.1126/science.241.4862.196.

Jennings, C. W., and W. A. Bryant (2010). Fault activity map of California, California Geol. Surv. Geol. Data Map 6, scale 1:750,000.
Lee, E.-J., and P. Chen (2017). Subsurface fault geometries in Southern California illuminated through Full-3D Seismic Waveform Tomography (F3DT), Tectonophysics 703/704, 42-49, doi: 10.1016/j.tecto.2017.03.005.

Lienkaemper, J. J., and C. Bronk Ramsey (2009). OxCal: Versatile tool for developing paleoearthquake chronologies-A primer, Seismol. Res. Lett. 80, 431-434, doi: 10.1785/gssrl.80.3.431.

Lin, J., and R. S. Stein (2004). Stress triggering in thrust and subduction earthquakes and stress interaction between the southern San Andreas and nearby thrust and strike-slip faults, J. Geophys. Res. 109, 02303, doi: 10.1029/2003JB002607.

Lozos, J. C. (2016). A case for historic joint rupture of the San Andreas and San Jacinto faults, Sci. Adv. 2, no. 3, e1500621, doi: 10.1126/ sciadv.1500621.

Lozos, J. C., D. D. Oglesby, B. Duan, and S. G. Wesnousky (2011). The effects of double fault bends on rupture propagation: A geometrical parameter study, Bull. Seismol. Soc. Am. 101, no. 1, 385-398, doi: 10.1785/0120100029.

Madugo, C. M., J. F. Dolan, and R. D. Hartleb (2012). New paleoearthquake ages from the Western Garlock fault: Implications for regional earthquake occurrence in Southern CaliforniaNew Paleoearthquake ages from the Western Garlock fault, Bull. Seismol. Soc. Am. 102, no. 6, 2282-2299, doi: 10.1785/0120110310.

McAuliffe, L. J., J. F. Dolan, E. Kirby, C. Rollins, B. Haravitch, S. Alm, and T. M. Rittenour (2013). Paleoseismology of the southern Panamint Valley fault: Implications for regional earthquake occurrence and seismic hazard in southern California, J. Geophys. Res. 118, no. 9, 5126-5146, doi: 10.1002/jgrb.50359.

Nicholson, C., A. Plesch, and J. Shaw (2017). Community Fault Model Version 5.2: Updating and expanding the CFM 3D fault set and its associated fault database, Poster Presentation at 2017 SCEC Annual Meeting, Palm Springs, California, 10-14 September.

Plesch, A., J. H. Shaw, C. Benson, W. A. Bryant, S. Carena, M. Cooke, J. Dolan, G. Fuis, E. Gath, L. Grant, et al. (2007). Community fault model (CFM) for Southern California Community fault model (CFM) for Southern California, Bull. Seismol. Soc. Am. 97, no. 6, 1793-1802, doi: 10.1785/0120050211.

Reimer, P. J., E. Bard, A. Bayliss, J. W. Beck, P. G. Blackwell, C. B. Ramsey, C. E. Buck, H. Cheng, R. L. Edwards, M. Friedrich, et al. (2013). Intcal13 and Marine13 radiocarbon age calibration curves 0-50,000 Years Cal BP, Radiocarbon 55, no. 4, 1869-1887.

Scharer, K., R. Weldon, G. Biasi, A. Streig, and T. Fumal (2017). Ground-rupturing earthquakes on the northern Big Bend of the San Andreas Fault, California, 800 A.D. to present, J. Geophys. Res. Article Number 2016JB013606, doi: 10.1002/2016JB013606.

Scharer, K., R. Weldon, A. Streig, and T. Fumal (2014). Paleoearthquakes at Frazier Mountain, California delimit extent and frequency of past San Andreas Fault ruptures along 1857 trace, Geophys. Res. Lett. 41, no. 13, Article Number 2014GL060318, doi: 10.1002/2014GL060318.

Scharer, K. M., and D. Yule (2020). A maximum rupture model for the Southern San Andreas and San Jacinto faults, California, derived from paleoseismic earthquake ages: Observations and limitations, Geophys. Res. Lett. 47, no. 15, Article Number e2020GL088532, doi: 10.1029/2020GL088532.

Scharer, K. M., G. P. Biasi, and R. J. Weldon (2011). A reevaluation of the Pallett Creek earthquake chronology based on new AMS 
radiocarbon dates, San Andreas fault, California, J. Geophys. Res. 116, no. B12, B12111, doi: 10.1029/2010JB008099.

Scharer, K. M., R. J. Weldon, T. E. Fumal, and G. P. Biasi (2007). Paleoearthquakes on the Southern San Andreas fault, Wrightwood, California, 3000 to 1500 B.C.: A new method for evaluating paleoseismic evidence and earthquake horizons, Bull. Seismol. Soc. Am. 97, no. 4, 1054-1093, doi: 10.1785/ 0120060137.

Seitz, G., R. Weldon, and G. P. Biasi (1997). The Pitman Canyon paleoseismic record: A re-evaluation of southern San Andreas Fault segmentation, J. Geodynam. 24, nos. 1/4, 129-138, doi: 10.1016/S0264-3707(96)00042-7.

Sieh, K. E. (1978). Prehistoric large earthquakes produced by slip on the San Andreas Fault at Pallett Creek, California, J. Geophys. Res. 83, no. B8, 3907-3939, doi: 10.1029/JB083iB08p03907.

Stuiver, M., and H. A. Polach (1977). Discussion: Reporting of ${ }^{14} \mathrm{C}$ data, Radiocarbon 19, no. 3, 355-364.

Toda, S., and R. S. Stein (2020). Long- and short-term stress interaction of the 2019 Ridgecrest sequence and Coulomb-based earthquake forecasts, Bull. Seismol. Soc. Am. 110, no. 4, 1765-1780, doi: 10.1785/0120200169.

Toppozada, T. R., D. M. Branum, M. S. Reichle, and C. L. Hallstrom (2002). San Andreas fault zone, California: $M \geq 5.5$ earthquake history, Bull. Seismol. Soc. Am. 92, no. 7, 2555-2601, doi: 10.1785/ 0120000614.

Weldon, R. J., T. E. Fumal, T. J. Powers, S. K. Pezzopane, K. M. Scharer, and J. C. Hamilton (2002). Structure and earthquake offsets on the San Andreas fault at the Wrightwood, California, paleoseismic site, Bull. Seismol. Soc. Am. 92, no. 7, 2704-2725, doi: 10.1785/0120000612.

Weldon, R. J., K. Scharer, T. Fumal, and G. Biasi (2004). Wrightwood and the earthquake cycle: What a long recurrence record tells us about how faults work, GSA Today 14, no. 9, 4-10, doi: 10.1130/ 1052-5173(2004)014<4:WATECW>2.0.CO;2.

Wesnousky, S. G. (2008). Displacement and geometrical characteristics of earthquake surface ruptures: Issues and implications for seismichazard analysis and the process of earthquake rupture displacement and geometrical characteristics of earthquake surface ruptures, Bull. Seismol. Soc. Am. 98, no. 4, 1609-1632, doi: 10.1785/0120070111.

Yang, W. J., and E. Hauksson (2013). The tectonic crustal stress field and style of faulting along the Pacific North America plate boundary in southern California, Geophys. J. Int. 194, no. 1, 100-117, doi: $10.1093 /$ gji/ggt113.

Manuscript received 23 June 2020 Published online 27 April 2021 